\title{
Zn-Containing Membranes for Guided Bone Regeneration in Dentistry
}

\author{
Manuel Toledano ${ }^{1}$, Marta Vallecillo-Rivas ${ }^{1}$, María T. Osorio ${ }^{2}$, Esther Muñoz-Soto ${ }^{1}$, Manuel Toledano-Osorio ${ }^{1}$, \\ Cristina Vallecillo ${ }^{1}{ }^{1}$, Raquel Toledano ${ }^{2}$, Christopher D. Lynch ${ }^{3, *}$, María-Angeles Serrera-Figallo ${ }^{4}$ \\ and Raquel Osorio ${ }^{1}$
}

Citation: Toledano, M.;

Vallecillo-Rivas, M.; Osorio, M.T.; Muñoz-Soto, E.; Toledano-Osorio, M.; Vallecillo, C.; Toledano, R.; Lynch, C.D.; Serrera-Figallo, M.-A.; Osorio, R. Zn-Containing Membranes for Guided Bone Regeneration in Dentistry. Polymers 2021, 13, 1797. https://doi.org/10.3390/polym13111797

Academic Editors: Begoña Ferrari,

Zoilo Gonzalez and

Ana Ferrandez-Montero

Received: 5 May 2021

Accepted: 25 May 2021

Published: 29 May 2021

Publisher's Note: MDPI stays neutra with regard to jurisdictional claims in published maps and institutional affiliations.

Copyright: (c) 2021 by the authors. Licensee MDPI, Basel, Switzerland. This article is an open access article distributed under the terms and conditions of the Creative Commons Attribution (CC BY) license (https:// creativecommons.org/licenses/by/ $4.0 /)$
1 Colegio Máximo de Cartuja s/n, Faculty of Dentistry, University of Granada, 18071 Granada, Spain; toledano@ugr.es (M.T.); mvallecillo@correo.ugr.es (M.V.-R.); emsoto@ugr.es (E.M.-S.); mtoledano@correo.ugr.es (M.T.-O.); cvallecillorivas@hotmail.com (C.V.); rosorio@ugr.es (R.O.)

2 Independent Research Scholar, Av. Fuerzas Armadas n1, 18014 Granada, Spain; mtoleosorio@gmail.com (M.T.O.); rtoleosorio@gmail.com (R.T.)

3 Restorative Dentistry, University Dental School \& Hospital, University College Cork, Wilton, T12 E8YV Cork, Ireland

4 Oral Surgery Section, Faculty of Dentistry, University of Sevilla, Avicena s/n, 41009 Sevilla, Spain; maserrera@us.es

* Correspondence: chris.lynch@ucc.ie; Tel.: +353-21-490-3000

Abstract: Barrier membranes are employed in guided bone regeneration (GBR) to facilitate bone in-growth. A bioactive and biomimetic Zn-doped membrane with the ability to participate in bone healing and regeneration is necessary. The aim of the present study is to state the effect of doping the membranes for GBR with zinc compounds in the improvement of bone regeneration. A literature search was conducted using electronic databases, such as PubMed, MEDLINE, DIMDI, Embase, Scopus and Web of Science. A narrative exploratory review was undertaken, focusing on the antibacterial effects, physicochemical and biological properties of Zn-loaded membranes. Bioactivity, bone formation and cytotoxicity were analyzed. Microstructure and mechanical properties of these membranes were also determined. Zn-doped membranes have inhibited in vivo and in vitro bacterial colonization. Zn-alloy and Zn-doped membranes attained good biocompatibility and were found to be non-toxic to cells. The $\mathrm{Zn}$-doped matrices showed feasible mechanical properties, such as flexibility, strength, complex modulus and tan delta. $\mathrm{Zn}$ incorporation in polymeric membranes provided the highest regenerative efficiency for bone healing in experimental animals, potentiating osteogenesis, angiogenesis, biological activity and a balanced remodeling. Zn-loaded membranes doped with $\mathrm{SiO}_{2}$ nanoparticles have performed as bioactive modulators provoking an M2 macrophage increase and are a potential biomaterial for promoting bone repair. Zn-doped membranes have promoted pro-healing phenotypes.

Keywords: zinc; membranes; bioactivity; guided bone regeneration; mechanical; microscopy; antibacterial; cytotoxicity

\section{Introduction}

The development of oral implantology has generated an increasing interest in procedures aimed toward maintaining and preserving both bone and soft tissue after tooth extraction. Followed by tooth loss, a process of bone remodeling occurs causing the reduction of socket dimensions [1]. This damage is more pronounced and close to $50 \%$ during the first three months [2]. To reduce the impact of this remodeling during alveolar healing, various techniques and materials have been studied to increase localized bone volume, making these regenerative procedures a main part of temporary implant therapy $[3,4]$ (Figure 1a). Periodontitis is a bacterial-mediated inflammatory process that affects both the gingiva and anchoring tissues of the tooth; if not treated, it may progressively destroy periodontal tissues, eventually resulting in tooth loss [4]. 


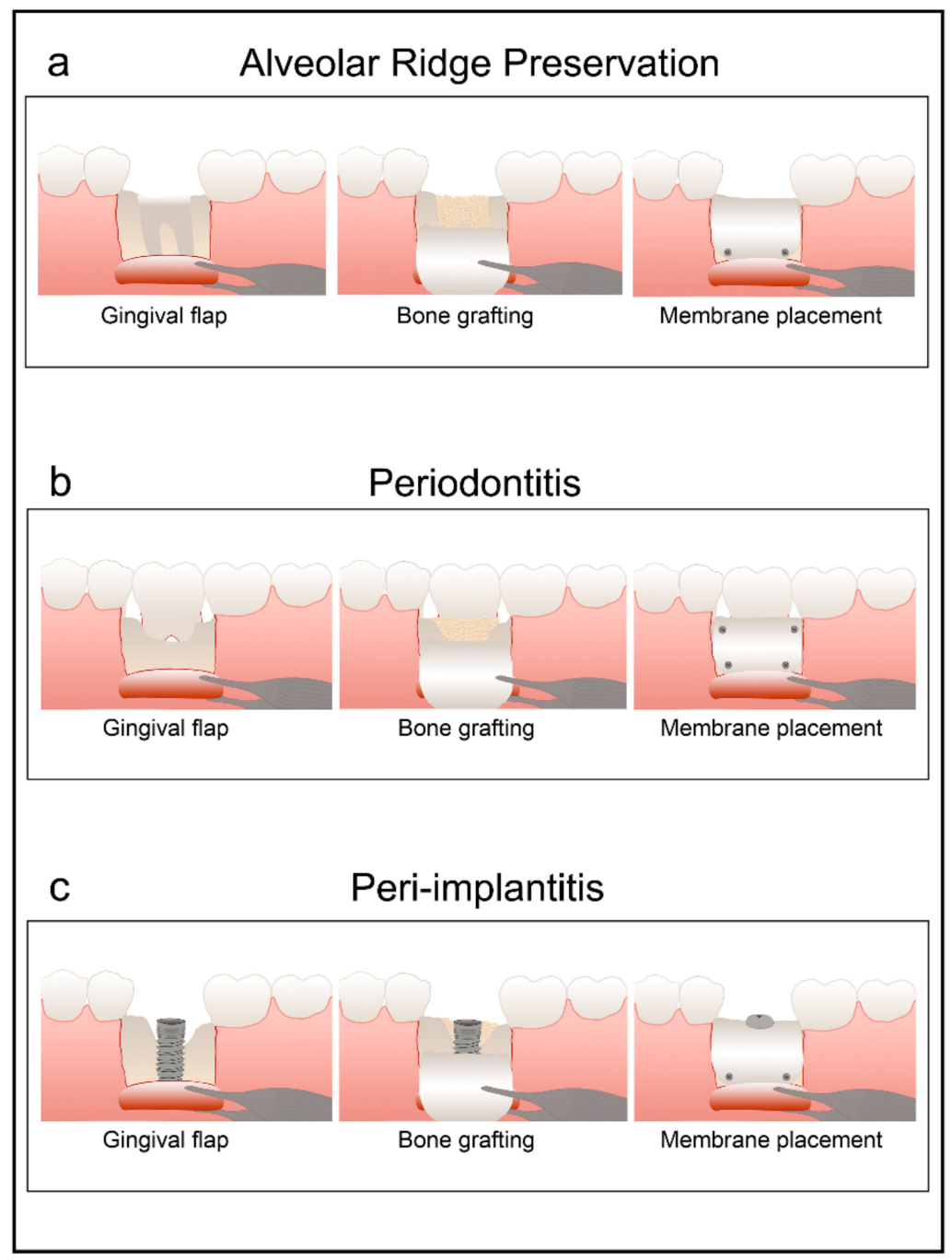

Figure 1. Illustration representing the surgical protocol for alveolar ridge preservation with membranes after tooth extraction (a). Use of membrane in regenerative procedures for periodontal defects (b). Membranes for peri-implantitis regeneration (c). In all cases, membranes are stabilized with mini-screws and pins to the surrounding bone.

Bone tissue engineering [5] has focused on the development of materials with the purpose of supporting bone formation, reducing the impact of bone remodeling and stimulating bone regeneration [6]. To achieve these goals, several biomaterials have been employed, including autologous bone, bone substitutes (allografts, xenografts, and alloplasts), blood [7] and active barrier membranes [8]. In this line, it has been recently shown from a clinical standpoint that quercetin-zinc complex incorporated into polycaprolactone/gelatin nanofiber can promote bone regeneration [9]. Anorganic bovine-derived hydroxyapatite/cell-binding peptide grafts have been proposed to treat intrabony defects in conventional periodontal surgery [10]. In order to provide bone cells within the secluded space for bone regeneration, a barrier membrane is placed to protect the clot within the socket and to isolate it from adjacent connective tissue [6,11]. This procedure is known as Guided Bone Regeneration (GBR). GBR can be applied in the treatment of both periodontitis (Figure 1b) and peri-implantitis (Figure 1c). Nevertheless, with this regenerative technique, long-term maintenance of enough space to provide sufficient bone is under question [12,13].

Available GBR membranes can be classified according to their resorbability characteristics. Collagen membranes are the most representative, characterized by their high 
biocompatibility and biodegradability [14]. However, they lack sufficient mechanical strength to remain stable over time and spatially protect the defect area [15]. When using non-resorbable membranes, the newly formed bone might have a protection from physiological stresses, which is required for remodeling and maturation. Non-resorbable membranes include expanded, high-density, titanium-reinforced polytetrafluoroethylene (PTFE), and titanium mesh [12]. PTFE is a synthetic polymer consider the gold standard against resorbable membranes. One drawback in the use of this type of membrane is the necessity for its removal with a second-stage surgical procedure [12]. Poly(e-caprolactone) pellets and gelatin type $B$ from bovine skin were used to construct an electrospun membrane with improved hydrophilicity and better cell-membrane response [4]. Polymethylmethacrylates (PMMA) are non-resorbable polymers that improve the mechanical performance of hydrophilic structures [16-18]. These biocompatible and biostable polymers exhibit weak interactivity with tissue cells and favor a biological response based on the formation of fibrotic tissue $[19,20]$. The bioactivity of these materials is mainly related to the absorption capacity of calcium, phosphate and bone-related proteins [20]. The failure or success of the implanted device is determined by a bioprocess recovery, highly influenced by adsorption of proteins [21], as they perform like bioactive molecules [22]. Proteins are constructed by amino acids functional groups as carboxyl $(\mathrm{COOH})$ and amino $\left(\mathrm{NH}_{2}\right)$. It has been demonstrated that cell differentiation and adhesion, and protein adsorption [23] may be altered by the modification of materials surfaces with those groups of amino acids [24]. A new proposal for composite membranes results from mixing (MMA) $)_{1}$-co-(HEMA) $)_{1}$ and $(\mathrm{MA})_{3}$-co-(HEA $)_{2}$ by electrospun [20]. These membranes perform as scaffolds that attempt to mimic the extracellular matrix (ECM) in both shape and size [20]. One of the main advantages of these types of membranes is the possibility to get their functionalization. This feature poses a pivotal breakthrough in current tissue engineering. Adding some extra components allows the modification of the physical and biological properties to improve the interaction with the surrounding tissue $[20,25]$.

Loading membranes with bioactive compounds can accelerate the bone formation process [26]. Recent studies have proposed to include some metallic materials, such as Feand Mg-based alloys, and more recently $\mathrm{Zn}$-alloys [14] to biodegradable matrices. $\mathrm{Zn}$ is an essential mineral that is vital for routine skeletal growth [9]. Zn can be found in the human body, being present in all tissues and more than 200 types of enzymes [14]. Zn participates in numerous physiological and metabolic processes, playing a fundamental role in the immune and nervous systems [27]. Electrospun polymer-based membranes loaded with $\mathrm{ZnO}$ have shown enhanced cell proliferation/wound healing [4]. Incorporation of $\mathrm{Zn}$ into a membrane for GBR favors the proliferation of osteoblasts [25], triggers bone neoformation and inhibits bacterial biofilm formation [28-30]. In addition, animal studies using Zn-doped nanostructured membranes show faster bone healing and regeneration $[9,30]$.

The present manuscript is a narrative review where previously published scientific evidence is summarized and synthesized. Nevertheless, this review does not follow rules about the search for evidence, and decisions about the importance of included manuscripts were not systematically performed. Systematic reviews, due to their methodology design, provides stronger evidence than narrative reviews, but it is difficult to perform a systematic review when the literature available and knowledge on the issue in question is scarce. In contrast to systematic reviews, narrative reviews can address one or more questions, and the selection criteria for inclusion of the articles may not be specified explicitly. Subjectivity in study selection is the main weakness ascribed to narrative reviews that potentially leads to biases. Certainly, the quality of a narrative review may be improved by borrowing from the systematic review methodologies that are aimed at reducing bias in the selection of articles for review and employing an effective bibliographic research strategy [31]. The aim of the present study was to state and assess the potential effectiveness of doping the membranes for GBR with zinc compounds in order to improve bone remineralization and regeneration. 


\section{Materials and Methods}

\subsection{Question Addressed by This Review}

Which benefits can be attributed to Zn-doped membranes in GBR?

\subsection{Literature Search}

An exploratory narrative review was conducted. Electronic databases, such as PubMed, Scopus, Web of Science, MEDLINE, DIMDI and Embase, were used to undertake the literature search. Additionally, after conducting a hand-searching of the literature, the references of similar and related studies were also included. Bone formation (MeSH Terms), bone regeneration (MeSH Terms), osteogenesis (MeSH Terms), "Zinc", "Zn", "Zinc-doped", "membrane", "membranes", "matrix", "scaffolds", "guide bone regeneration", "GBR", "alveolar ridge preservation" and "periodontal regeneration" were the main search terms. There was no time limit established and English-written articles were only selected. The included articles in the present narrative review were those in which the main objective was to study $\mathrm{Zn}$-containing membranes and establish their benefits if applied in oral surgery and periodontology. After deep reading of the included articles, performance of membranes containing $\mathrm{Zn}$ was evaluated by means of bioactivity and remineralization assessment, antibacterial effects and physicochemical properties of the membranes, microstructure, mechanical properties and so cells cytotoxicity and proliferation onto membranes.

\subsection{Eligibility: Inclusion and Exclusion Criteria for Studies}

Inclusion of an article was based on the following inclusion criteria: Studies assessing the effectiveness of $\mathrm{Zn}$-containing membranes by comparing changes in bioactivity, degree of remineralization and regeneration, antibacterial potential, physicochemical-mechanical properties, microstructure, cytotoxicity and cells proliferation. Then, the present preselected studies were evaluated according to the following exclusion criteria:

1. Insufficient information on type or zinc content.

2. Duplicate studies, commentaries and letters to the editor.

\subsection{Preparation of Zn-Doped Membranes for Guided Bone Regeneration}

\subsubsection{Zn Phosphate Mineralized Collagen Membrane}

Polyglycolic acid/trimethylene carbonate (PGA/TMC) copolymer membrane. Resolut Adapt LT (W.L. Gore \& Associates, Inc., Flagstaff, AZ, USA), and bovine-derived collagen membrane, BioMend Extend (Zimmer Dental, Carlsbad, CA, USA) [32], were cut into $1 \mathrm{~cm}^{2}$ sections and mineralized. Two methods: (i) the precipitation method, consisting in incubating each section in $20 \mathrm{~mL}$ zinc phosphate solution (potassium phosphate and zinc acetate) for 3 and 7 days at $37^{\circ} \mathrm{C}$; and (ii) the microwave method developed by LeGeros et al., [32,33], immersing each section in $20 \mathrm{~mL}$ of zinc phosphate solution and placing it in the microwave oven, activated on medium power until the solution evaporates completely. The membranes were then rinsed with double distilled water and allowed to air dry.

\subsubsection{Composite Membrane of Zn Bioactive Glass and Polylactic Acid}

Bioactive Glass and poly-L-D-L-lactic acid (PLDLA) were used. To prepare zinccontaining bioactive glass (ZnBG) powders, Oh et al., [34] set precursors in appropriate concentrations $\left(70 \mathrm{SiO}_{2}-25 \mathrm{CaO}-5 \mathrm{ZnO}\right)$ that were dissolved in ethanol-water solvent which contained $\mathrm{HCl}$, and stirred for $6 \mathrm{~h}$. After $24 \mathrm{~h}$ aging at $40^{\circ} \mathrm{C}$, the solution was dried for several days at $70{ }^{\circ} \mathrm{C}$. The gelled product was heat-treated to $650{ }^{\circ} \mathrm{C}$, held there for $3 \mathrm{~h}$, and then cooled to room temperature. To prepare ZnBG powders, the resulting powders of heat-treatment were pounded and sieved down to $45 \mu \mathrm{m}$, dissolved in tetrahydrofuran (THF) and mixed with PLDLA at $4 \%(w / v)$ for elaboration of composite membranes with polylactic acid (PLA). The glass/PLDLA composition was fixed at $\sim 3 / 7$ by weight to maintain an important mechanical flexibility and a great amount of glass. Finally, to form a membrane of $\sim 150 \mathrm{~mm}$ thickness, the solution was agitated for $24 \mathrm{~h}$ and put into a teflon 
mold to evaporate the solvent. After incubation of the membranes in a simulated body fluid, the surface morphology and the crystalline phase were evaluated with field emission scanning electron microscopy (FESEM) and X-ray diffraction (XRD), respectively. The mechanical properties were measured by applying a tensile load at a speed of $1 \mathrm{~mm} / \mathrm{min}$ using an Instron 3344.

\subsubsection{Composite Membrane of Poly( $\varepsilon$-caprolactone), Gelatine Type B from Bovine Skin and $\mathrm{ZnO}$ Nanoparticles}

Poly( $\varepsilon$-caprolactone) pellets and gelatine type B from bovine skin and $\mathrm{ZnO}$ nanoparticles were used to construct an electrospun membrane. The polymers were dissolved in hexafluoruro-2-propanol to produce a $10 \mathrm{wt} \%$ solution $\left(100 \mathrm{mg} \mathrm{mL}^{-1}\right)$ stirred overnight and added at different concentrations relative to the total polymer weight. The obtained materials were collected and dried under vacuum for at least $48 \mathrm{~h}$ to complete removal of solvents [4]. The membranes were observed by FESEM, energy dispersive X-ray spectroscopy (EDX), transmission electron microscopy (TEM) and Fourier transform infrared spectroscopy (FTIR). Contact angle, mechanical properties, antimicrobial activity and cytotoxicity tests were also performed. A mixture containing $\mathrm{CaO}: \mathrm{CaHPO} 4: \mathrm{ZnO}=0.7: 2: 0.3$ (molar ratio) was used by Chou et al., 2014 [26] to produce the zinc hydroxyapatite (ZnHAp) powder samples, which were ground in an agate centrifugal ball mill. Gelatine blocks were completely dissolved in $60^{\circ} \mathrm{C}$ water for $3 \mathrm{~h}$ at a $5 \%(\mathrm{wt})$ concentration, cooled to $40{ }^{\circ} \mathrm{C}$ in ice, mixed with $\mathrm{Zn}$-HAp powders at $70 \mathrm{mg} / \mathrm{mL}$ concentration and then were $12 \mathrm{~h}$ air-dried to produce the membranes. Before being freeze-dried for $12 \mathrm{~h}$, membranes were allowed to swell for $1 \mathrm{~h}$ in $4^{\circ} \mathrm{C}$ distilled water. Finally, the membranes were crosslinked by heat at $150{ }^{\circ} \mathrm{C}$ for $5 \mathrm{~h}$. Powder XRD analysis was used to evaluate Zn-HAp powders. The thickness and the morphological features of the surface were observed under SEM. Two derivatives of $\mathrm{Zn}$ (II) quercitin [(Zn(quercitin) $\left.\mathrm{H}_{2} \mathrm{O}_{2}\right)(\mathrm{Zn}+\mathrm{Q})$, and $\mathrm{Zn}$ (quercitin) (phenanthroline) $(\mathrm{Zn}+\mathrm{Q}(\mathrm{PHt})]$ were synthesized and characterized using UV-Visible spectrophotometer and Fourier Transform-IR spectroscopy. The UV-Visible absorption and IR spectra prove the B-ring chelation of the flavonoid quercetin to $\mathrm{Zn}$ (II) rather C-ring chelation. At the molecular level, Runx2, mRNA and protein, ALP and type 1 collagen mRNAs, and osteoblast-specific microRNA, pre-mir-15b were examined using real-time RT-PCR and Western blot assay [9].

\subsubsection{Polymeric Membranes with Zinc Ions Complexation}

The membranes were prepared with a commercial polymeric mixture (PolymBlend ${ }^{\circledR}$ ) [18]. PolymBlend ${ }^{\circledR}$ is made of a blend of two copolymers with high molecular weight: (i) [(MA) $3^{-}$ co-(HEA) $)_{2}$ (average Mw 2000 kDa, PDI < 1.5) and (ii) [(MMA) $)_{1}$-co-(HEMA) $)_{1}$ (average $\mathrm{Mw}$ $200 \mathrm{kDa}$, PDI < 2.5). A non-woven nanofiber material with adequate physicochemical and mechanical properties was produced by electrospinning. Before electrospinning, purification of cured copolymers (three dissolutions in acetone and precipitation of monomer in water) was used to discard unreacted monomers. After the creation of the nano-structured membranes (NMs), the nanofiber membrane was heat-treated and immersed it in hot water $\left(60{ }^{\circ} \mathrm{C}\right.$ ) for $4 \mathrm{~h}$. Protein adsorption was determined for zinc-doped NMs- $\mathrm{NH}_{2}$ (aminated) and NMs-COOH (carboxylated) membranes. Then, the membranes were loaded, by chemical functionalization, with zinc (Zn-NM) (40 ppm, for $3 \mathrm{~d}, \mathrm{pH}$ 6.5) and incubated for 3 days at room temperature [28]. The attained ion complexation values were $3 \mu \mathrm{g} \mathrm{Zn} / \mathrm{mg}$ of membrane. To reach equilibrium of adsorption of metal ions, they were shaken in different solutions of $\mathrm{ZnCl}_{2}$ (composed of zinc $40 \mathrm{ppm}$ and pH 6.5) (Figure 2) and then, suspensions were centrifuged for $60 \mathrm{~min}$ (two cycles, $12.000 \mathrm{rpm}$ ). After centrifugation, the matrices were separated from the supernatant [29]. For the surface preactivation, a sodium carbonate buffer solution ( $333 \mathrm{mM}$ and $\mathrm{pH}$ 12.5) was used to react with $\mathrm{Zn}$-matrix and $\mathrm{OH}$-matrix surfaces for $2 \mathrm{~h}$ and then gently washed with water. Therefore, carboxyl groups were arranged on their surfaces due to the partial hydrolysis of ester bonds [17]. A new polymer blend was recently synthesized starting from $(\mathrm{MA})_{3}$-co-(HEA) $)_{2} /(\mathrm{MMA})_{1}$-co-(HEMA) but further comprises $5 \%(\mathrm{wt})$ of $\mathrm{SiO}_{2}$ nanoparticles $\left(\mathrm{SiO}_{2}-\mathrm{NPs}\right)$, suspending them in the 
electrospinning solution (Figure 3). In the membrane, $\mathrm{SiO}_{2}$-NPs were homogenously dispersed and also trapped in the whole fiber volume forming a solid solution (composite) [6] To functionalize the Zn-loaded membranes, the ability of carboxyl groups to complex divalent cations was used. Two types of membranes were manufactured: (1) $\mathrm{SiO}_{2}-\mathrm{NP}$ doped membrane (HOOC-Si-Membrane) and (2) $\mathrm{SiO}_{2}-\mathrm{NP}$ doped membrane functionalized with Zn (Zn-HOOC-Si-Membrane).

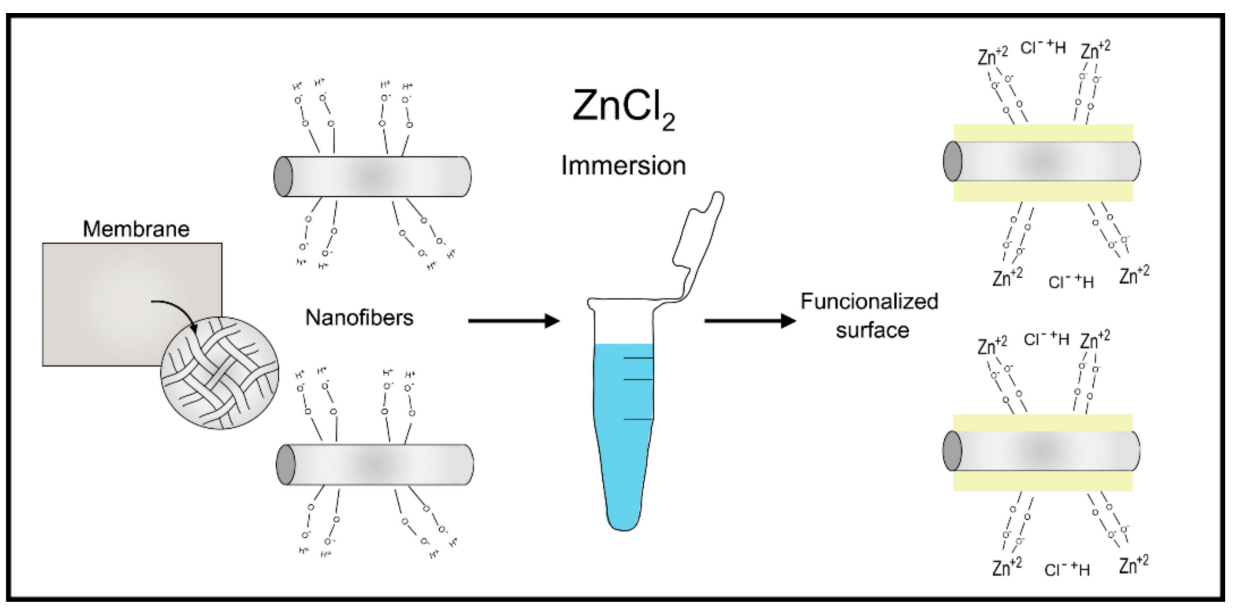

Figure 2. The carboxyl-terminal on polymeric Zinc-doped membranes surfaces, after their immersion on $\mathrm{ZnCl}_{2}$.

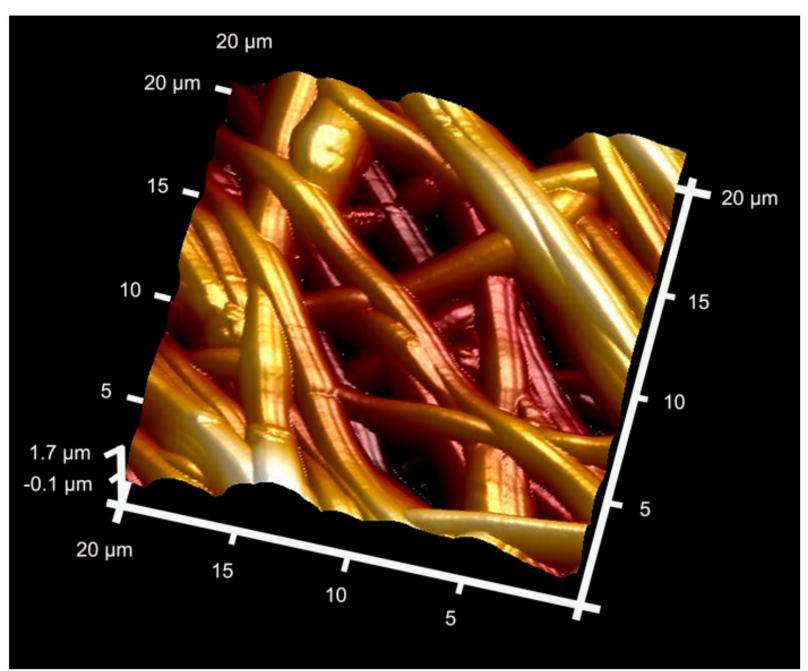

Figure 3. AFM image of the surface's Zn-matrix. Overlapped and randomly distributed nanofibers may be observed. Spotty nanodeposits, at high magnification, are distributed onto the Zn-fiber surfaces.

\subsubsection{Membranes Composed by Zn-Li-Mg, Zn-Li and Zn-Li-Ag Alloys}

Zhang et al., 2019 [14] prepared pure $\mathrm{Zn}, \mathrm{Li}, \mathrm{Mg}$ and $\mathrm{Ag}(>99.9 \%)$ membrane. To formulate $\mathrm{Zn}-0.8 \% \mathrm{Li}-0.2 \% \mathrm{Mg}(\mathrm{wt}), \mathrm{Zn}-0.8 \% \mathrm{Li}(\mathrm{wt})$, and $\mathrm{Zn}-0.8 \% \mathrm{Li}-0.2 \% \mathrm{Ag}(\mathrm{wt})$ alloys. Ingot dimensions $(\varnothing 60 \mathrm{~mm} \times 200 \mathrm{~mm}$ ) were achieved through melting samples in graphite crucibles at $580^{\circ} \mathrm{C}$ in a resistance furnace under an Ar atmosphere and then cast into a $550{ }^{\circ} \mathrm{C}$ cylindrical steel mold. Inductively coupled plasma atomic emission spectrometry (ICP-AES) was used to analyze alloy composition. To homogenize the structure, it was annealed at $400{ }^{\circ} \mathrm{C}$ for $24 \mathrm{~h}$ and cooled in water. Finally, sheets with a thickness of $0.1 \mathrm{~mm}$ were obtained by placing in a box furnace at $250{ }^{\circ} \mathrm{C}$ and then hot rolling them with intermediate annealing. 


\section{Results}

\subsection{Antibacterial Effects of Zn-Loaded Membranes}

The minimum inhibitory concentration differed in all concentrations tested for function of the bacteria species [4]. All the membranes containing distinct concentrations of $\mathrm{ZnO}$ showed antibacterial activity against the studied bacteria, with relevant inhibition zones ranging from 6 to $15 \mathrm{~mm}$ in diameter, being the caprolactone $30 \%$ the highest effective.

To determine the antibacterial effect, the mean bacterial colony forming between 4 and $48 \mathrm{~h}$ for zinc-loaded membranes was evaluated and then compared with those non-mineralized by immersing each membrane in an Actinobacillus actinomycetemcomitans culture. Comparing the mean colony forming unit value for mineralized collagen membranes between 4 and $24 \mathrm{~h}$ showed more than a 3-fold drop at $24 \mathrm{~h}$ mean in antibacterial effect. The difference in the overall mean colony forming unit value between mineralized collagen membranes and non-mineralized collagen membranes was statistically significant [32]. The antibacterial effects of non-mineralized and $\mathrm{Zn}$ phosphate mineralized membranes were also evaluated at different incubation times, and decreased at $48 \mathrm{~h}$. Among the membranes tested, mineralized collagen membranes achieved better antibacterial effects than non-mineralized and $\mathrm{Zn}$ phosphate mineralized membranes. The non-mineralized membranes attained significantly higher counts of bacterial colonization compared to $\mathrm{Zn}$ phosphate mineralized membranes.

Periodontal biofilms were studied by Bueno et al., 2020 [28] after $12 \mathrm{~h}, 48 \mathrm{~h}$ and $72 \mathrm{~h}$ by scanning electron microscopy (SEM). After 12, 24, 48 and $72 \mathrm{~h}$, DNA of growth biofilms was isolated and then quantified using PCR for the six bacterial species used. Each DNA sample was analyzed in duplicate and the correlation between quantification cycle $(\mathrm{Cq})$ values and CFU mL-1 were generated through a software. As shown by SEM, NMs doped with zinc resulted in structured biofilms from 12-72 $\mathrm{h}$. Quantitative evolution of the bacterial load revealed a lower total number of bacterial on NMs doped with $\mathrm{Zn}$ ( $\mathrm{Zn}-\mathrm{NMs}$ ) compared to control biofilms up to $48 \mathrm{~h}$. At $72 \mathrm{~h}$, this effect was lost, and a significantly higher bacterial count was found on Zn-NMs.

\subsection{Physicochemical and Biological-Related Properties of Zn-Loaded Membranes}

Due to the physiological conditions, the release of zinc ions from the membranes was studied by the authors in an acetate base ( $\mathrm{pH}$ 4.5) and a phosphate base solution. Crystallographically, by powders XRD analysis, the peak patterns verified signature peaks associated with amorphous HAp. Mass spectroscopy showed Zn concentration to be approximately $5 \%$. Morphologically, crater-like structures characterized the surface of membranes. The thickness of the membranes resulted to be roughly $100 \mu \mathrm{m}$ [26]. The release pattern of $\mathrm{Zn}$ showed an initial burst release in the first $12 \mathrm{~h}$ before reaching an equilibrium concentration after $40 \mathrm{~h}$; the levels remained constant until the 72-h mark. The acidic nature of the solution degraded some parts of the membranes [26]. In Toledano et al., 2020 [20], both $\mathrm{NMs}^{-\mathrm{NH}_{2}}$ and NMs-COOH membranes attained similar fibronectin (Fn) and plasma proteins (PP) adsorption. NMs-COOH membranes adsorbed significantly more albumin than $\mathrm{NMs}-\mathrm{NH}_{2}$. $\mathrm{NMs}-\mathrm{NH}_{2}$ membranes adsorbed significantly more fibrinogen (Fg) than NMs-COOH.

\subsection{The Effect of Zn-Loaded Membranes on Bioactivity and Bone Formation}

The precipitation of calcium phosphate on the PLDLA-ZnBG started at day 3 and was pronounced at day 7 , covering the surface almost completely. The crystalline phase developed was characteristic of apatite [34].

In vitro tests of bioactivity showed mineral nanodeposits of $100 \mathrm{~nm}$ placed on the surface of the fibers in a random way [18]. Calcium and phosphorus were found on the surface of the nanofibers that composed the membrane, in the EDX spectrum. Numerous agglomerations of more than $200 \mathrm{~nm}$ of spherical ZN nanocrystals were detected (Figure 4). Furthermore, calcium, phosphorus and zinc appeared after the elemental analysis of crystal agglomerations. 


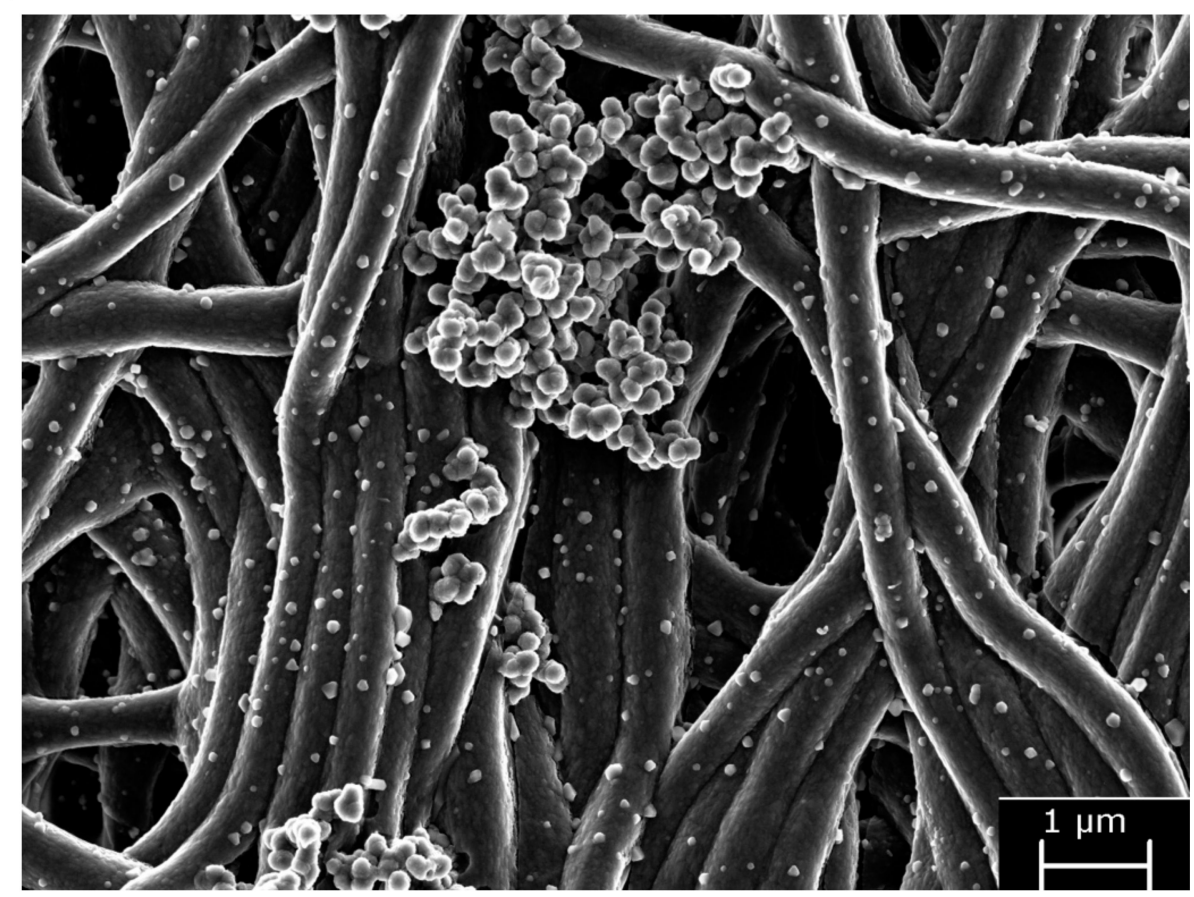

Figure 4. FESEM micrographs of a Zn-doped membrane after immersion in SBFS. Nanofiber diameter is about $500 \mathrm{~nm}$, and fibers lost the smooth appearance of their surface. Nanodeposits of mineral $(100 \mathrm{~nm})$ are randomly distributed onto the nanofiber surfaces. Numerous agglomerations of other spherical nanocrystals (bigger than $200 \mathrm{~nm}$ ) are identified onto the Zn-matrix surface.

In vivo test used thirty, non-adult, Wistar rats due to their adequate size for evaluating membranes and response to implanted biomaterials. These 15-week-old animals were randomly divided into experimental groups. Every 2 weeks until 6 weeks, new bone formations were evaluated with a software based on the CT scans $(40 \mu \mathrm{m} /$ pixel voxel size) [26]. Zn-doped membranes achieved statistically more new bone formation in comparison to the unloaded groups. At 6 weeks, the bone recovery at the defect site from Zn-doped membranes was 75\% approximately. At 6 weeks, the newly generated bone in the $\mathrm{Zn}$-doped group reached a maturation level identical to that of the surrounding host bone. At both Toledano et al., 2019 and 2020 [6,30] microcomputed tomography (micro-CT) was used to analyze rabbit skulls. The average bone density (HU) was assessed by a PMOD software, and BoneJ (ImageJ plugin) was employed to evaluate bone architecture. Six white, New Zealand-breed rabbits composed the sample with the same characteristics regarding age, 6 months, and weight, $3.5-4 \mathrm{~kg}$. Von Kossa morphometric study of the regenerated bone defects was carried out to visualize the mineralized bone, obtaining information about osteoid surface (OS), bone surface (BS), percentage of osteoid surface $(\mathrm{OS} / \mathrm{TS})$ and bone perimeter $(\mathrm{BPm})$, bone thickness (BTh), and percentage of bone area (BS/total surface (TS)). To observe the deposition of calcein into the newly deposited bone matrix, fluorescence images were obtained. Osteoblasts, osteocytes, and blood vessels were evaluated at toluidine blue (TB) images. Osteoclasts, macrophages (M1 and M2 and ratio $\mathrm{M} 1 / \mathrm{M} 2)$, were also assessed.

The Crop analysis performed in Toledano et al., 2019 [30] showed that compared to the control, Zn-NMs produced a higher BS. Zn-NMs presented a greater number of branches and junctions, trabecular bone, when the skeleton analysis was performed. When observing the center of the defect (culture 150) with micro-CT, Zn-NMs showed higher characteristics of Euler and bone spatial connectivity compared with control. The analysis skeleton through micro-CT permitted to observe higher nodes, branch points and longer branches, increased new bone formation (BS/TS ratio), greater BTh and higher OS than the control group. Interstitial connective tissue was visible in samples treated with Zn-NMs. TB staining showed reactionary bone formed with lacunae bridging of 
osteocytes on the Zn-NMs. Observing Zn-NMs, new bone formation could be seen both below and outside the membrane, while on both sides of it few isles of new bone were observed. These isles presented, from the limits of the defect, a stockade of osteoblasts and osteoid (Figures 5 and 6 ). No signs of inflammation infiltrate could be observed. While the osteocytes count was similar between the different groups, osteoblasts were found in greater numbers in $\mathrm{Zn}-\mathrm{NMs}$ (Figures 5 and 6). These osteoblasts appeared immediately on contact with the membrane in some fields. Many large vessels could be detected in samples treated with Zn-NMs (Figures 7 and 8).

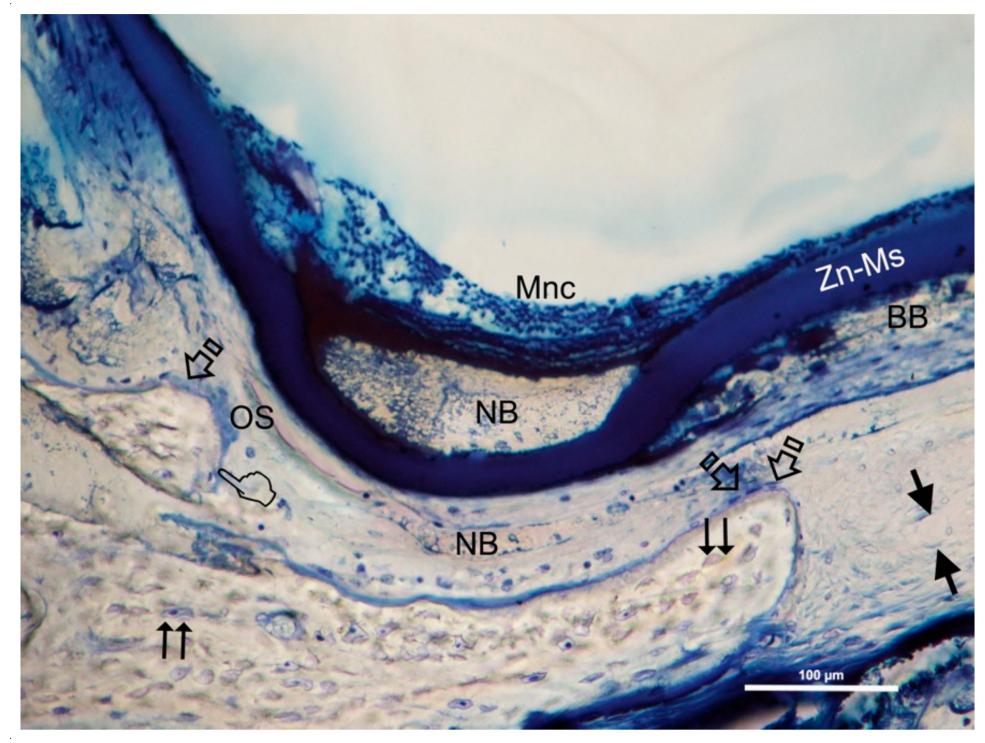

Figure 5. Bone histology image obtained by dye with toluidine blue after using Zn-NMs, in experimental animals after their healing time. Few isles of newly formed trabecular bone (NB) were observed at both side of Zn-NMs. Single arrows point the presence of osteoblasts; double arrows mean osteocytes and pointers indicate osteoclast. Face arrows mean blood vessels. Bony bridging (BB), mononuclear cells (Mnc) and osteoid (Os) may be observed.

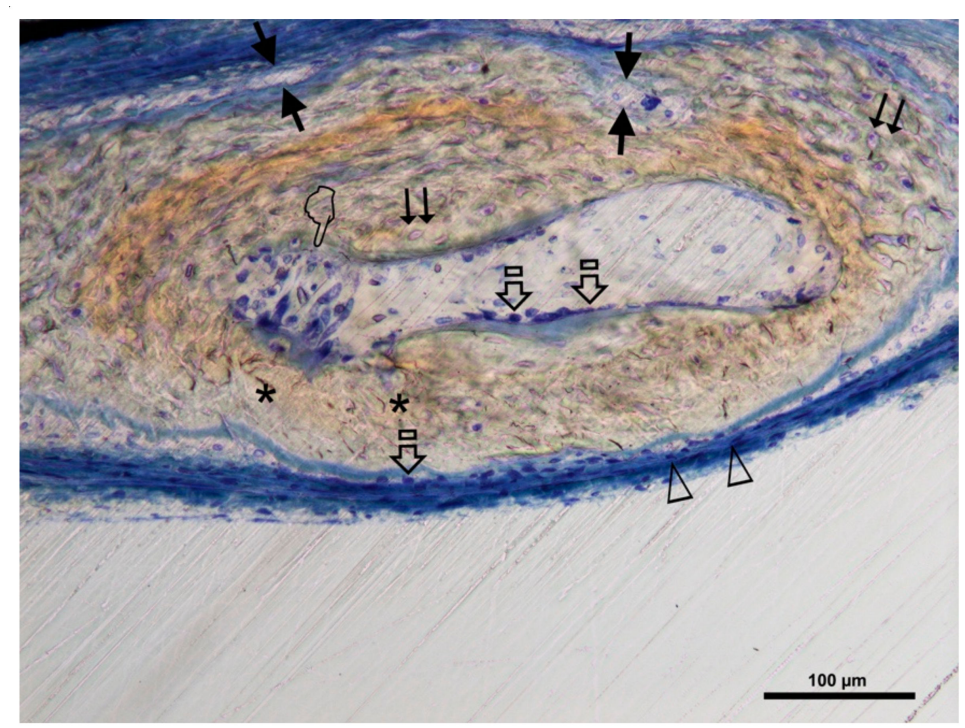

Figure 6. Bone histology image obtained after using Zn-NMs dye with toluidine blue in experimental animals to visualize mineral bone after their healing time. Single arrows point the presence of osteoblast with typical cuboid shape. Double arrows indicate osteocytes, pointers mean osteoclast and faced arrows point blood vessels. Asterisk are located close by canaliculi. Arrow heads signal the presence of osteoid. 


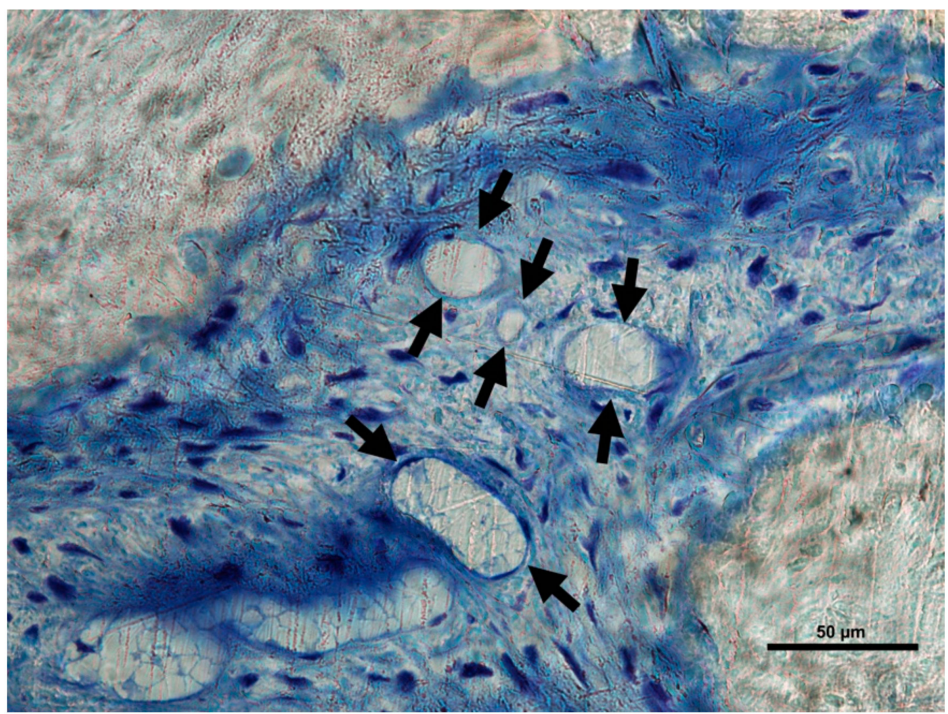

Figure 7. Bone histology image obtained in samples treated with Zn-loaded membranes by coloration with toluidine blue in experimental animals. At high magnification, vessels are clearly visualized (faced arrows) promoting and maintaining bone maturation.

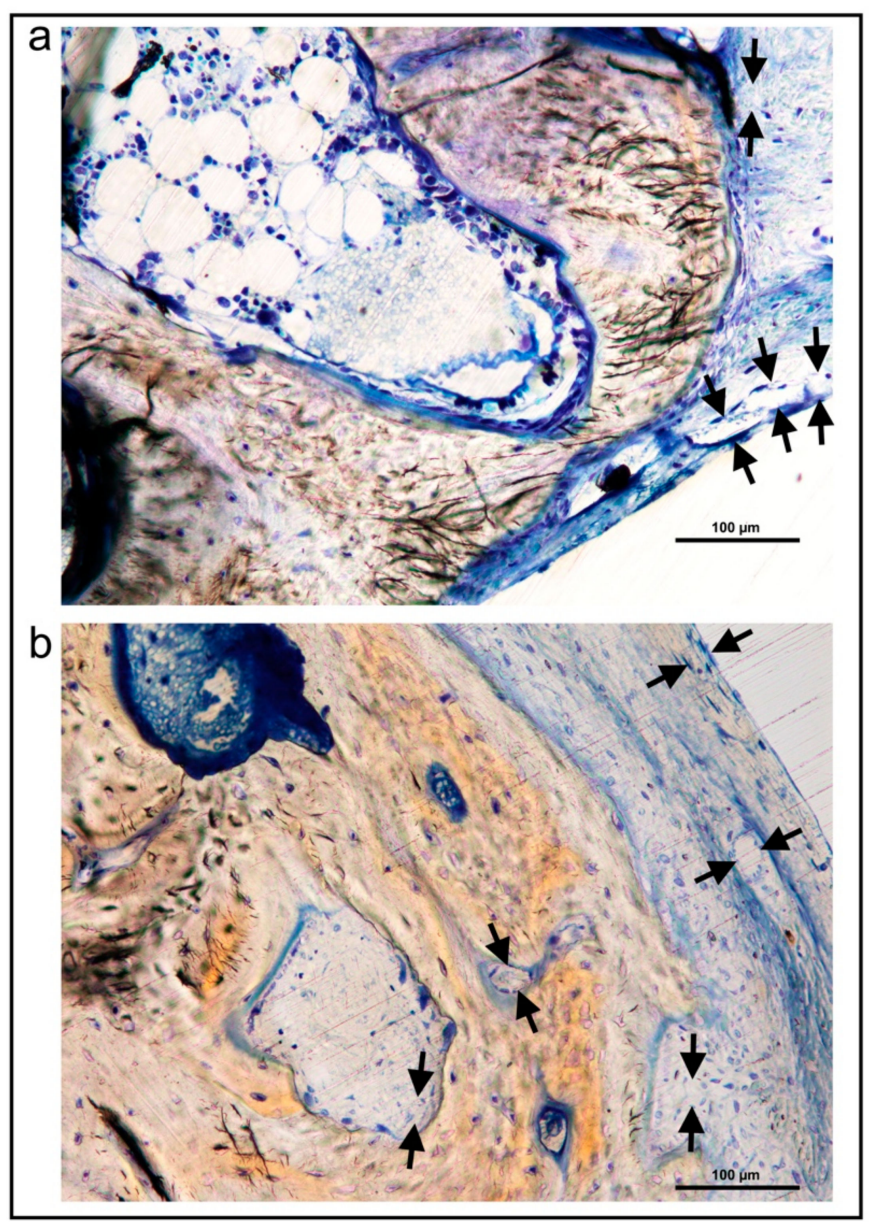

Figure 8. Bone histology images obtained by dye with toluidine blue after using Zn-loaded membranes in experimental animals. Blood vessels (faced arrows) that connect bone marrow directly with the blood supply can be easily observed $(\mathbf{a}, \mathbf{b})$. 
The chick embryo chorioallantoic membrane (CAM) assay demonstrated that the angiogenic parameters were increased by the $(\mathrm{Zn}+\mathrm{Q}(\mathrm{PHt}))$ complex. Meanwhile, the $(\mathrm{Zn}+\mathrm{Q}(\mathrm{PHt}))$ complex showed significant activity and thereby this complex was further examined for the bone tissue activity by incorporating the complex into a nanofiber through electrospinning method [9].

\subsection{Analysis of the Microstructure through Microscopic Characterization}

Microstructure was examined by SEM and TEM, whose specimens thinned $80 \mu \mathrm{m}$; the constituent phases were identified by XRD [14]. Homogeneous (from 56 to $1184 \mathrm{~nm}$ ) and heterogeneous (from 93 to $2223 \mathrm{~nm}$ ) diameter distribution was observed in caprolactone and caprolactone-gelatin-based membrane, respectively [4]. The NPs showed, basically, a rod-like profile. The fibers showed some swollen areas and distinct areas embedded with $\mathrm{ZnO}$ NPs. All membranes attained $\mathrm{C}-\mathrm{H}$ bond of saturated carbons and the ester-carbonyl group (-CO stretching).

Surface nanoroughness (SRa) was examined, in Osorio et al., 2017 [18], Osorio et al., 2020 [29] and Toledano-Osorio et al., 2021 [25], using atomic force microscopy (AFM). A specific software (Nanoscope) was employed to measure fiber to fiber distance and fiber diameters with ImageJ. Attached to an EDX, FESEM was used to perform an additional surface characterization to analyze membranes and look for phosphate and calcium deposits. XRD was used to detect crystal formation and its main components. Mean and standard deviation of nanofiber sizes ranged from 302.40 (SD 19.13) to 312.72 (SD 28.66) $\mathrm{nm}$ from AFM observations [18]. The fiber size was approximately $300 \mathrm{~nm}$ in diameter, through FESEM analysis (Figure 4). Microfibers had a size ranging from 2.05 (SD 0.30) to 1.97 (SD 0.18) nm. Fiber to fiber distances were in a wide range, between 110 and $11.5 \mu \mathrm{m}$. Zn-loaded tissues showed a SRa of 108.40 (SD 16.17) nm. Zn-Li and Zn-Li-Ag alloys were composed of a $\mathrm{Zn}$ matrix with a secondary $\mathrm{LiZn}_{4}$ phase, whereas the Zn-Li-Mg alloy consisted mainly of a $\mathrm{Mg}_{2} \mathrm{Zn}_{11}$ phase, in the proposal of Zhang et al., 2019 [14]. Ag was completely dissolved in the Zn matrix. Microstructure of alloys containing Zn showed a fibrous structure along with the rolling direction, where the grains and the secondary phase were crushed, lengthened into a fibroid, and distributed along the rolling direction. In the $\mathrm{Zn}$-Li-Mg alloy, an intermediate phase $\left(\mathrm{Mg}_{2} \mathrm{Zn}_{11}\right)$ with an elliptical shape uniformly appeared in the $\mathrm{Zn}$ matrix. The secondary phase was confirmed to be $\mathrm{Mg}_{2} \mathrm{Zn}_{11}$ and was not observed for the Zn-Li-Ag alloy. Zn-Li showed fine grains and small subgrains, implying that recrystallization occurred during the rolling process. A large number of spherical particles were homogeneously distributed inside the grain, attributed to the secondary $\mathrm{LiZn}_{4}$ phase. The Zn-Li alloy had precipitation size of approximately 10-30 nm, with a high density.

\subsection{In Vitro Mechanical Behavior of Zn-Doped Membranes}

PLDLA-ZnBG membranes showed similar tensile strength that the undoped membranes and so high degree of elongation and flexibility [34].

Under a hydrated condition of the specimens, Hysitron TI Premier nanoindenter equipped with a nano-DMA software (DMA-III) was employed to conduct nanomechanical property mappings, in Osorio et al. [18,29]. Loss modulus $(E)$, complex modulus ( $\left.E^{*}\right)$, tan delta $(\delta)$, and storage modulus $\left(\mathrm{E}^{\prime}\right)(\mathrm{GPa})$ were calculated. Zn-matrices achieved a complex modulus of 17.40 (5.36) GPa, a loss modulus of 6.60 (1.44) GPa, a storage modulus of 13.29 (5.25) GPa and a tan delta $\delta$ of 0.65 (0.15) in Osorio et al., 2017 [18] (Figure 9). The Zn-Li alloy showed a high yield strength $(183.5 \pm 5.3 \mathrm{MPa})$, ultimate tensile strength $(238.1 \pm 4.7 \mathrm{MPa})$ and elongation $(75 \pm 6 \%$ ) [14].

\subsection{Cells Cytotoxicity and Proliferation}

To assess the in vitro cellular behavior, rat bone marrow mesenchymal stem cells (rBMSCs) were used in Oh et al., [34]. Cell viability and morphology were determined using an ELISA reader and confocal laser scanning microscopy, respectively. Cells were viable, 
with high total protein content, for PLDLA-ZnBG membranes, showing well-developed cytoskeletal filaments in active stretching [34]. There was a significant alkaline phosphatase rise and activity with increasing culturing time, after the presence of $\mathrm{Zn}$ [14]. Zn content also promoted the growth of osteocalcin. The mineralization quantified demonstrated a significantly higher Ca level on the PLDLA-ZnBG membranes. Zn-Li-Ag alloy was innocuous and satisfactory for bone tissue engineering in the study attained by Zhang et al., 2019 [14].

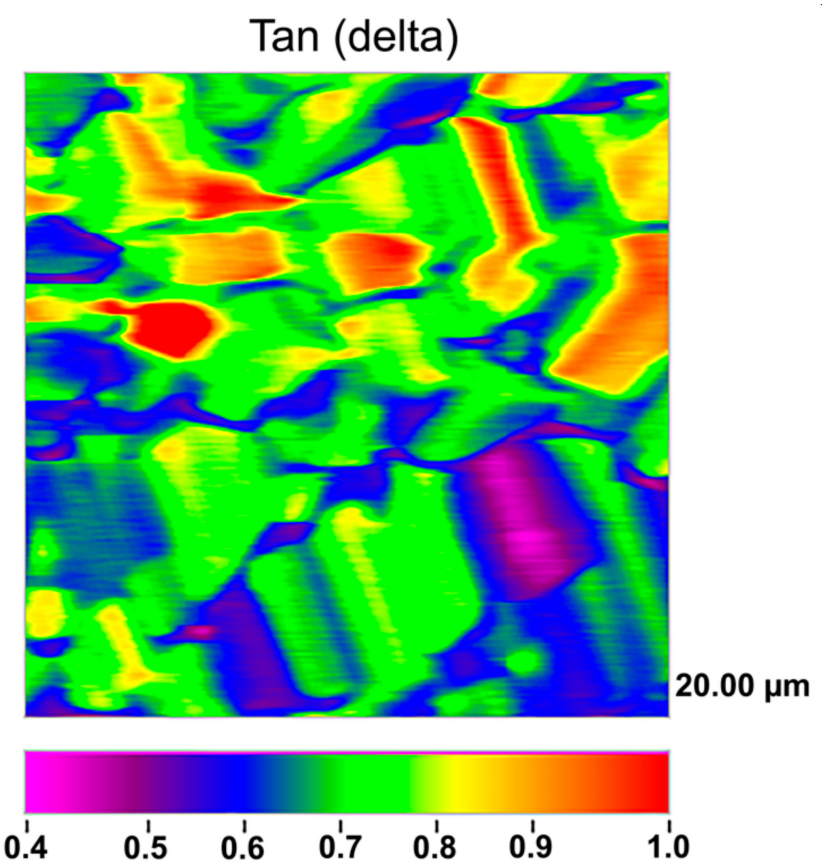

Figure 9. Nano-DMA analysis, on scanning mode, of the surface's Zn-matrix. The property map corresponds to the tan delta values.

Münchow et al., (2015) [4] reported cytocompatibility in all membranes. Nevertheless, the presence of a higher concentration of NPs led to a brief toxic effect on the cells, being the caprolactone-gelatine presentation the material having the highest cytotoxic potential.

Primary cultures of human oral mucosa fibroblasts [18] were obtained to determine cell viability by three different techniques: (1) cell death, quantifying DNA liberated to the culture media; (2) the lactate dehydrogenase (LDH) assay, detecting the amount of LDH which is released by cells with damaged membrane; and (3) fluorescence-based method to evaluate cell membrane integrity and cytoplasmatic esterase function, quantifying the number of green (live) and red (death) cells (LIVE/DEAD). Liberated DNA to the culture media was found to be very low in Osorio et al. [18]. Human fibroblasts viability stated above $80 \%$ in zinc-loaded groups. All the experimental groups attained high levels of cell viability. Zn-loaded membranes produced a negligible degree of cytotoxicity, and a dose-dependent effect was not noticed after applying any test. Osorio et al., 2020 [29] used Alamar-Blue ${ }^{\mathrm{TM}}$ assay to determine cell proliferation. FESEM was utilized to study cell morphology.

\section{Discussion}

There are multiple factors to be studied on the present membranes. Multi-parametric characterization comprises the study of surface characteristics such as porosity, pore size and roughness, mechanical properties of the surface, in vitro static bioactivity and biological characterization by cell culture methods are required $[11,25,35]$. 


\subsection{Antibacterial Effects of Zn-Loaded Membranes}

The antibacterial effect of zinc phosphate mineralized collagen and zinc phosphate mineralized copolymer membranes has been demonstrated [32]. This antibacterial effect on mineralized membranes of zinc phosphate, collagen or copolymer, which results from the inhibition of bacterial colonization, favors the regeneration and healing of both soft and hard tissues [36]. Increased concentration of $\mathrm{ZnO}$ did not inhibit zones against Porphyromonas gingivalis, but against Fusobacterium nucleatum that antibacterial activity was greater at $10,000 \mu \mathrm{g} / \mathrm{mL}$ [4]. NPs can produce reactive oxygen species which may penetrate the cell wall and affect bacterial integrity. The higher the amount of NPs incorporated, the greater the availability of active compound to diffuse into the agar and inhibit bacterial growth. Even more, gelatine can interact with the cell membrane promoting its destruction/death. Polymeric NMs loaded with $\mathrm{Zn}$ were able to alter the kinetics and development of in vitro biofilms [28]. However, this antibacterial effect decreased when the biofilms reached the stationary phase $(72 \mathrm{~h})$. The loss of antimicrobial effect is explained by the full coverage of the NMs surface by non-vital bacterial cells [28]. In addition, it has been previously claimed the importance of modifying the membrane's structure by adding metal components as zinc to achieve antibacterial effect [25].

\subsection{Physicochemical and Biological-Related Properties of Zn-Loaded Membranes}

For the development of a biodegradable Zn-HAp membrane, zinc hydroxyapatite powder was incorporated into gelatine solutions [26]. The membrane production process was relatively simple, and the result was a biomaterial with a rough surface, which would encourage cell activity. This Zn-HAp membrane has shown the potential to be used in GBR, allowing the release of ions (zinc, phosphate and calcium) on the defect, stimulating bone regeneration in rat calvaria. Some of the demonstrated characteristics of the membrane are cellular adaptation, immobility, differentiation, and the permeation of vital nutrients and growth factors for GBR [26,37-39]. It has been speculated that when osteoclasts adhere to the rough surface of the membrane and were liberated into the localized area, zinc ions, along with calcium and phosphate, would be released. Hence, they would depress osteoclast bone resorption by inducing osteoclast apoptosis, promoting osteoblast differentiation and proliferation [26]. It was shown that bone formation was faster compared to samples testing collagen membrane or in specimens without membrane. In the Zn-NMs group there was a recovery and regeneration of the defect from the second week. This process continued throughout the study period, demonstrating a more complete and unified remodeling mechanism [26]. The staining analysis of hematoxylin and eosin did not reveal any signs of fibroblast infiltration. The newly deposited bone on the membrane showed well-distributed bone formation with similar maturation and thickness patterns than the original bone. This process of bone creation occurred before the $\mathrm{Zn}-\mathrm{NMs}$ reabsorption. Osteogenesis happens along the surface of $\mathrm{Zn}-\mathrm{NMs}$ probably due to the higher concentration of Ca ions compared to the collagen membrane.

At polymeric carboxylated membranes immersed in Kokubo solution, calcium phosphate deposits were created. However, a lack of bioactivity was stated for the aminated membranes, due to calcium ions in SBF which are apt to be trapped by the double scissors of COO-function. Then, the still bounded calcium ions attracted negatively charged phosphate ions from the solution [40] to form a columnar Ca framework in calcium phosphate deposits. Furthermore, it has been reported that HAp formation was successfully achieved with weaker acidic $-\mathrm{PO}_{4} \mathrm{H}_{2}$ and $-\mathrm{COOH}$, but not with - $\mathrm{OH}$ and $-\mathrm{CH}-\mathrm{CH}_{2}$ [41]. Notably, the $-\mathrm{COOH}$ end group appeared to provide the optimal surface for nucleation and growth of biomimetic HAp [20].

\subsection{The Effect of Zn-Loaded Membranes on Bioactivity and Bone Formation}

The use of zinc in bone tissue engineering has become increasingly important, as more and more studies have shown the influence of Zn-HAp on the osteoblast proliferation and bone regeneration. It has been demonstrated that if osteoblasts are exposed to $\mathrm{Zn}$ ions, 
the production of transforming growth factor-beta (TGF- $\beta$ ) is favored and increases the production of osteoprotegerin (OPG) [26]. OPG is responsible for inhibiting osteoblast differentiation and function by acting as a decoy for osteoclast receptor activators of nuclear factor kappa- $\beta$ ligand (RANKL). Chou et al., [26] after evaluating in an animal model, a membrane functionalized with zinc, confirmed the barrier properties and the response of the host tissue to the use of Zn-NMs. Histological evaluation of the samples showed good cell separation and new bone formation. The bone formation around Zn-NMs was well distributed throughout the membrane and defect with a maturation and thickness similar to the original bone. Zn-NMs achieved osteogenesis thanks to the presence of calcium ions in higher concentration on its surface. These properties confirm the intrinsic and important role of zinc in bone tissue formation demonstrating the relationship that does exist between $\mathrm{Zn}$, bone remodeling and regeneration processes. Then, the influence of $\mathrm{Zn}-\mathrm{NMs}$ can be potentially advantageous for clinical applications [26].

The in vitro bioactivity of a material is defined as the ability to create bony bonds with the host bone. It can be predicted from the formation of calcium phosphate $(\mathrm{Ca} / \mathrm{P})$ deposits on the surface after simulated body fluid solution (SBFS) immersion [42,43]. Ca/P deposition can be explained as a surface phenomenon [44]. Osorio et al., 2017 [18] demonstrated that after immersion in SBFS, zinc is found in the hard tissues favoring the precipitation of $\mathrm{Ca} / \mathrm{P}$ deposits and the generation of HAp nanocrystals. Zinc deposits on tissues helped for phosphate group binding. These phosphate groups have poorly coordinated oxygens, resulting in reactive surfaces that will attract calcium ions from SBFS [45]. The biomimetic $\mathrm{Ca} / \mathrm{P}$ deposition, inspired by the natural biomineralization process, is considered a coating method even capable of generating periodontal regeneration. The presence of HAp determines bone formation and osteoconduction since this molecule favors the formation of bone apatite-like materials, being able to promote cells recruitment [46]. Osteoblasts, cementoblasts, periodontal ligament and pulp cells stimulated with extracellular $\mathrm{Ca}^{2+}$ and $\mathrm{PO}_{4}{ }^{2-}$ increased bone morphogenetic protein-2 (BMP-2) mRNA expression $[8,47,48]$. Increases in $\mathrm{Ca}^{2+}$ concentration is related to higher levels of the fibroblast growth factor-2 (FGF-2) gene and protein expression, in the periodontal ligament [49]. FGF-2 is responsible for neoformation, has a mitogenic effect on cementoblasts and cells of the periodontal ligament, and improves the regeneration of periodontal tissue. It also accompanied the formation of new bone and cementum with functionally oriented periodontal ligament fibers [49]. The main advantage of the chemical formulation of the presented matrices is that they possess a high calcium-binding affinity, which is essential for cell differentiation and bone regeneration. Moreover, direct covalent binding and immobilization of a high load of almost any type of biomolecule (enzyme, growth factors, antibody, antigen, antibiotic ... ) at their surfaces have been encountered [18].

Precipitation of calcium and phosphate on the matrix surfaces was observed in zincloaded specimens [18]. The increase in structural indexes, through tomographic analysis that was observed after Zn-NMs application [30] resulted in the replacement of older, overly mature bone with younger and more resilient bone [50]. Osteoid or bone matrix that will be, but not yet, mineralized [51] showed higher surface than in the control group when Zn-NMs were used, a sign of young new bone formation [52]. The pattern of the tissue appeared composed by Zn-NMs in close contact with the newly formed bone and with osteoid. The significant increase of mineralized bone matrix excluding osteoid [51] (Figure 10) was related to an increase in osteoblasts prompted by all membranes in comparison with the control group, especially when Zn-NMs were used. Newly formed bone, associated with multiple interconnected ossified trabeculae, was observed directly in contact with the Zn-NMs surfaces in the regions that showed successful bone conduction [53]. The newly formed bone was continuous in some exploration sections, forming bony bridges from the margin of the defect and without invasion of soft tissue (Figures 5 and 10). The changing osteonal morphology is probably related to the maturation and maintenance of the bone vasculature, which is a clear sign of remodeling, based on both nutrient supply and cell recruitment [54] (Figures 8 and 9). Osteogenesis is always preceded by 
angiogenesis [55]. Therefore, it is logical to think that the incorporation of $\mathrm{Zn}$ provides a greater regenerative efficiency during bone healing (Figures 6 and 11). Not only the osteogenesis was determined, but also the improved biological activity according to the number of osteoblasts when Zn-NMs were used.

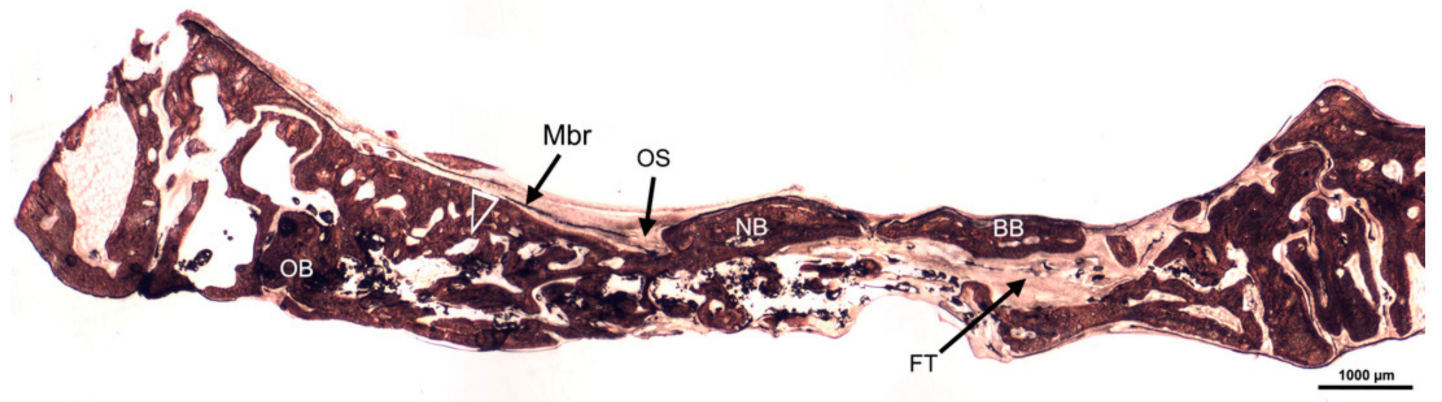

Figure 10. Bone histomorphometry obtained by dye with Von Kossa silver nitrate stain to visualize formed mineralized bone in experimental animals at six weeks of follow-up, around Zn-loaded membranes. Trabecular bone formations were formed along the margin of calvarial defect and within the defect (arrow head). Bony bridging (BB), Fibrous tissue (FT), Membrane (Mbr), Osteoid (OS), Old bone (OB).

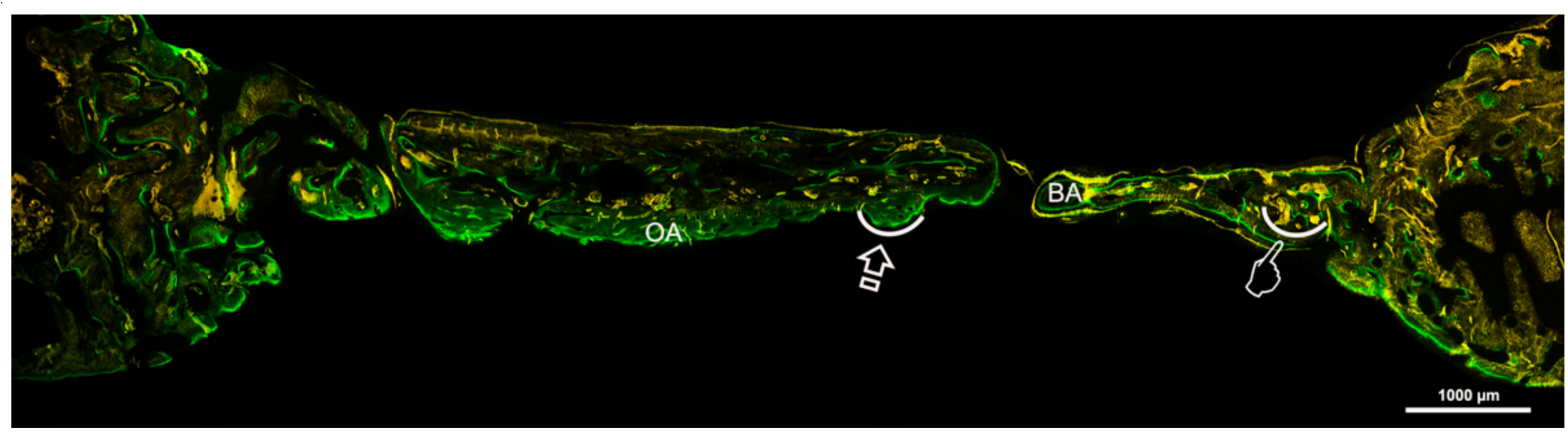

Figure 11. Bone histology obtained by fluorescence with calcein at the region of interest to see mineralized bone, at six weeks of healing time after using Zn-loaded membranes. Pointers indicate bone perimeter and arrows signal osteoid perimeter. Bone area (BA), Osteoid area (OA).

The zinc ion is considered a promising osteoimmunomodulator acting on macrophage polarization and conditioning the differentiation of osteogenic cells [56]. Bone formation is a sign that the membranes are capable of causing osteoblast growth and differentiation to fill, completely or partially, the intracortical pores with nucleating clusters. These mineral deposits will subsequently fuse, resulting in amorphous $\mathrm{Ca} / \mathrm{P}$ and finally apatite crystals [57], to reactivate the cells of the bone lining into bone-forming osteoblasts. The connectivity of the pores described in these membranes [18] could influence the possibility that a greater number of osteoblasts can penetrate the porous structure [58]. Zn has been shown to protect both collagen from degradation [16] and seed crystallite-sparse collagen from remineralization. $\mathrm{Zn}$ also influences the signaling pathway and stimulates the metabolic effect of hard tissue mineralization [59]. Zn-NMs act as bioactive modulators of the signals communicated to the underlying defect. These results provide evidence that Zn-NMs may be useful for tissue engineering but should be viewed with caution until corroborated in clinical studies.

\subsection{Analysis of the Microstructure through Microscopic Characterization}

The membrane of ZnBG-PLDLA was shown to be flexible when handled, suggesting the possible applicability for a dental biomaterial within a periodontal pocket [34]. The increase viscosity of the gelatine-based solutions plus caprolactone may lead to the occurrence of thicker fibers compared to those gelatine-free [4]. Addition of higher amount of 
$\mathrm{ZnO}$ NPs increases the electrical conductivity of the polymer, reducing the self-repulsion tension and the elongation forces, hence reducing fibers width. Nanometric porosity ranging from 50 to $500 \mathrm{~nm}$ selectively enhances protein adsorption (including fibronectin and vitronectin), contributing to cell attachment $[18,60]$. Cells growing on membranes containing pores between 5 and $8 \mu \mathrm{m}$ showed increased osteogenic differentiation [61]. These pore sizes are frequently encountered in the presented tissues, being approximately $30 \%$ of pores on each tissue. Dynamic recrystallization occurred during the rolling processing in the study attained by Zhang et al., 2019 [14]. The average grain size of the Zn-Li-Ag alloy $(2.3 \mu \mathrm{m})$ was smaller than that of the $\mathrm{Zn}-\mathrm{Li}$ alloy $(4.1 \mu \mathrm{m})$, indicating that adding an Ag alloying element refined the grains of the $\mathrm{Zn}-\mathrm{Li}$ alloy. The high density of fine dispersive precipitates could impede the dislocation movements, leading to a strength increase for alloy. The precipitates also showed a regular interface [14].

\subsection{In Vitro Mechanical Behavior of Zn-Doped Membranes}

ZnBG-PLDLA membranes retained sufficient level of mechanical strength and flexibility for space maintenance and handling [34]. They also inducted a Ca/P mineral phase on the surface within a relatively short period. Blending gelatine in junction with caprolactone increases the crystallinity and mechanical strength of fibers [4]. Crosslinking reactions contributed to improved mechanical properties and degradation resistance. The $\mathrm{ZnO}$ incorporation revealed a decrease of both the tensile strength and the Young's modulus. Storage moduli of Zn-matrices are within the range of the nanoindentation moduli of calcified trabecular bone, which are about $15 \mathrm{GPa}[18,62]$. These values highly differ from the storage modulus calculated for highly cross-linked collagen scaffolds, which is around $1 \mathrm{GPa}$ [63]. The importance of these results is supported by a recent finding stating that substrate stiffness can modify cell behavior and cells may probe and respond to mechanics in fibrillar matrices [64]. They presented the highest ability to store potential energy which is released after deformation. Dissipation of energy within the structures is of prime importance in dynamic systems $[65,66]$, such as the oral function, where oral structures require damping to absorb shock waves and alleviate stresses. Hence, improving damping characteristics becomes imperative for enhancing their robustness and force resistance. During contact, low-modulus materials lead to stress concentration resulting in transfer of energy (without dissipation) from the tissues to the adjacent structures. Zn-matrices attained adequate tan $\delta$ values (0.6), being more favorable to cell spreading as recently published by Baker et al., 2015 [64]. In Zhang et al., 2019 [14], the Zn-Li alloy showed a ductile fracture surface with dimples and a few shear lips, indicating that the plasticity of the Zn-Li alloy could be theoretically improved. The $\mathrm{Zn}-\mathrm{Li}(\mathrm{Mg}, \mathrm{Ag})$ alloys prepared exhibited high tensile properties (especially plasticity), superior to those of reported $\mathrm{Zn}$-based alloys such $\mathrm{Zn}-\mathrm{Mg}$ or $\mathrm{Zn}$-Ca alloys. The excellent mechanical properties could be ascribed to the precipitation strengthening, the grain refinement and to the dynamic recrystallization [14].

\subsection{Cells Cytotoxicity and Proliferation}

All membranes, in Münchow et al., 2015 [4], presented cell viability higher than 50\% and was optimal even when $\mathrm{ZnO}$ content up to $15 \%$, thus confirming the biocompatible nature of the $\mathrm{ZnO}$-incorporated membranes. Nevertheless, incorporation of a higher amount of NPs provoked a slight toxic effect on the cells. At low concentration $(<5 \mathrm{wt} . \%)$, $\mathrm{ZnO}$ was not harmful to cells. When mesenchymal stem cells were cultured on the ZnBGPLDLA membranes, the cells were shown to adhere favorably and continued to actively proliferate with time, having adequate growth kinetics. The osteoblastic development was satisfactory, enhancing the mineralization process of the ECM of cells developed on the substrate [34]. Matrices of $\mathrm{Zn}$-loaded membranes were found to be non-toxic to fibroblast in all the assays performed by Osorio et al., 2017 [18], where Zn-loaded scaffolds presented a very low cytotoxic effect. The morphology of L929 cells after 5 days of incubation in different extract mediums with concentrations of 10, 50, and 100\% showed that L929 cells were healthy and exhibited a flattened spindle shape, similar to that of negative control [14]. 
Osorio et al., 2017 [18] stated that the inclusion of calcium and zinc ions on the membranes' surface are not cytotoxic, as it was highlighted above. However, metals accumulation in the body may also be considered. It has been reported for the different studied GBR Zn-containing membranes that the biological significance of a metal concentration depends on the specific tissue in which the metal is deposited, and toxicity cannot be predicted from total metal burden in the organism [67]. Recent studies have shown that zinc exhibits better in vivo degradation behavior without leaving voluminous corrosion products that are hard to be eliminated by human body [68]. According to ISO 10993-5: 1999, the cytotoxicity of these extracts of Zn-Li-Ag alloy was of Grade 0-1. In other words, the Zn-Li-Ag alloys are innocuous and satisfactory for bone tissue engineering [14]. It can be concluded that the incorporation of metallic nanoparticles to the biomaterial did not exert cytotoxicity and avoided adverse effects on the organisms. Quercetin-zinc complex ( $\mathrm{n}+\mathrm{Q}(\mathrm{PHt}))$ incorporated into polycaprolactone/gelatin nanofiber acted as a pharmacological agent for treating bone associated defects and guided bone regeneration [9]. Histology studies revealed that the (PCL/gelatin/Zn $+\mathrm{Q}(\mathrm{PHt}))$ showed in-vivo biocompatibility [9].

The $\mathrm{Zn}$-containing membranes have not shown zones of inhibition against certain bacteria (Porphyromonas gingivalis) [4]. The antibacterial activity of $\mathrm{ZnO}$-loaded membranes was found to be dose-dependent ( $\geq 5 \mathrm{wt} . \%$ ) [69]. Increased concentration of $\mathrm{ZnO}$ could reduce bacterial load and counts of the tested bacterial species but when the biofilms reached $72 \mathrm{~h}$ phase the antimicrobial effect of the Zn-NM decrease. It has been explained that the full coverage of the NMs surface by non-vital bacterial cells may have helped for this decrease of antimicrobial effect [28]. The incorporation of high ZnO NPs content might decrease the fiber thickness [4]. This slimming process also might hinder the cell colonization process and angiogenesis for a proper guided bone regeneration [6]. $\mathrm{ZnO}$ nanoparticles possess high surface energy, so they tend to agglomerate when mixed in higher concentrations, forming clusters along the fiber and, consequently, causing a significant morphological change. These characteristics may also negatively influence cell proliferation, cell colonization process and angiogenesis for a proper guided bone regeneration. However, the combination with gelatin allows the incorporation of a greater amount of $\mathrm{ZnO}$ without damaging changes in morphology and microstructure [4]. On the other hand, simple $\mathrm{Zn}$-Li alloys create thicker grain size precipitates within the sheets formulated by Zhang et al., (2019) [14]. Nevertheless, they proposed to include an Ag alloying group aimed to refine the grains of the $\mathrm{Zn}$-Li alloy [14]. Besides, the plasticity of the $\mathrm{Zn}-\mathrm{Li}$ alloy has been demonstrated to be scarce and, at least in theory, should be improved by trying to incorporate other Zn-based alloys [14].

$\mathrm{ZnO}$ nanoparticles are not soluble in water. At higher $\mathrm{ZnO}$ contents (e.g., 30 wt.\%) the surface energy of the membrane could be reduced, thus resulting in lower wettability [4]. Optimal wettability is important at GBR, since the membranes are placed in direct contact with fluids present in the surgical site [70]. It has been also pointed out that the $\mathrm{ZnO}$ inclusion may show a decrease of the tensile strength and the Young's modulus, but the manufacturers offset this drawback by incorporating crosslinking reactions [4]. ZnO NPs inclusion on the same polymers increased membranes' cell cytotoxicity in a dose-dependent manner obtaining a reduction in cell viability up to $50 \%$; therefore, $\mathrm{ZnO}$ concentration should be maintained under certain limitation [4].

In order to improve and expand the clinical applications of functionalized nanostructured membranes, other substances and molecules may be used for loading. The possibility that the matrices presented could be chemically functionalized and loaded with almost any type of biomolecule (enzyme, growth factors, antibody, antigen, antibiotic...) on their surfaces, presents a wide field of study $[18,25]$. However, it is important to determine whether this membrane adds clinical advantages to the existing membranes for guided tissue regeneration. In vitro studies demonstrated that surface chemistry (hydrophilicity, surfaces with carboxyl groups) and nanotopographies play an important role on cell behavior and tissue integration based on macrophage polarization [6,29,30]. Ongoing 
experiments using large animal models are needed to check immunomodulation capacity and osteogenic differentiation.

\section{Conclusions}

Zinc phosphate mineralized membranes, compared with non-mineralized membranes, have a significantly greater antibacterial effect, inhibiting bacterial colonization in vivo and so avoiding inflammation process and bone resorption. The Zn-Li-Ag alloy had a great biocompatibility, along with a resistance to corrosion and adequate mechanical properties. Zinc carbonate and zinc oxide were the main corrosion products. ZnBG-PLDLA membranes have shown appropriate mechanical properties such as strength and flexibility. The presence of $\mathrm{ZnBG}$ enhanced the osteogenic differentiation of the stem cells as confirmed by alkaline phosphatase, osteocalcin and sialoprotein, as well as the cellular mineralization. Precipitation of calcium and phosphate on the matrix surfaces was observed in zinc-loaded polymeric membranes, and these matrices were found to be non-toxic to cells. Even when the incorporation of metallic nanoparticles to the membranes did not exert cytotoxicity and seem to avoid adverse effects on the organisms, it has to be acknowledged that long-term human assays are scarce. Low amount of zinc oxide nanoparticles improves the bioactivity of the membranes.

Experimental carboxylate membranes adsorbed higher concentration of tested proteins leading to major cells adhesion, proliferation and membrane integration into the surrounding tissue. The precipitation of calcium phosphate on the membrane surface was facilitated by membranes functionalized with carboxyl groups, which may lead to a rapid mineralization of the membrane. Incorporation of $\mathrm{Zn}$ in the membranes and their use for bone healing at rabbits calvarial provided the highest regenerative efficiency. Zn-loaded membranes promoted osteogenesis and enhanced biological activity, as mineralized and osteoid new bone with multiple interconnected ossified trabeculae, but without soft tissue invasion, appeared in close contact with the membrane. Zn-loaded Si-modified membranes showed the lowest ratio M1/M2, modulating the polarization of macrophages toward prohealing phenotypes. Zn-HOOC-Si-Membranes obtained a balanced remodeling, enhanced biological activity and attained the best regenerative efficiency after angiogenesis and osteogenesis assessments. The bone-integrated Zn-HOOC-Si-Membranes may provide a novel therapeutic approach and can be considered as bioactive modulators, which increase M2 macrophages and so promoting bone repair. Quercetin-zinc complex ( $\mathrm{Zn}+\mathrm{Q}(\mathrm{PHt}))$ incorporated into polycaprolactone/gelatin nanofiber acted as a pharmacological agent for treating bone associated defects and guided bone regeneration.

Author Contributions: Conceptualization, M.T., M.V.-R., M.T.-O., C.V., and R.O.; Formal analysis, M.T., M.T.O., M.T.-O., R.T. and R.O.; Funding acquisition, M.T. and R.O.; Investigation, M.T., M.V.-R., M.T.O., M.T.-O., E.M.-S., C.V., R.T., C.D.L., M.-A.S.-F. and R.O., Methodology, M.T., M.V.-R., M.T.O., M.T.-O., C.V., R.T. and R.O.; Project administration, M.T. and R.O.; Supervision, M.T.; Validation, M.T., M.T.O., M.T.-O., R.T. and R.O.; Visualization; M.T., M.T.-O. and R.O.; Writing—original draft, M.T., M.V.-R., M.T.O., M.T.-O., E.M.-S., C.V., R.T. and R.O.; Writing-review and editing, M.T., M.T.-O., C.D.L. and R.O. All authors have read and agreed to the published version of the manuscript.

Funding: This work was funded by the University of Granada/Regional Government of Andalusia Research Fund from Spain and European Regional Development Fund (A-BIO-157-UGR-18/FEDER).

Institutional Review Board Statement: Not applicable.

Informed Consent Statement: Not applicable.

Data Availability Statement: The data presented in this study are available on request from the corresponding author.

Acknowledgments: The authors would like to thank E. Osorio for kindly offering the original images presented at Figures 3 and 9 from her collection, which has allowed us to illustrate this work.

Conflicts of Interest: The authors declare no conflict of interest. 


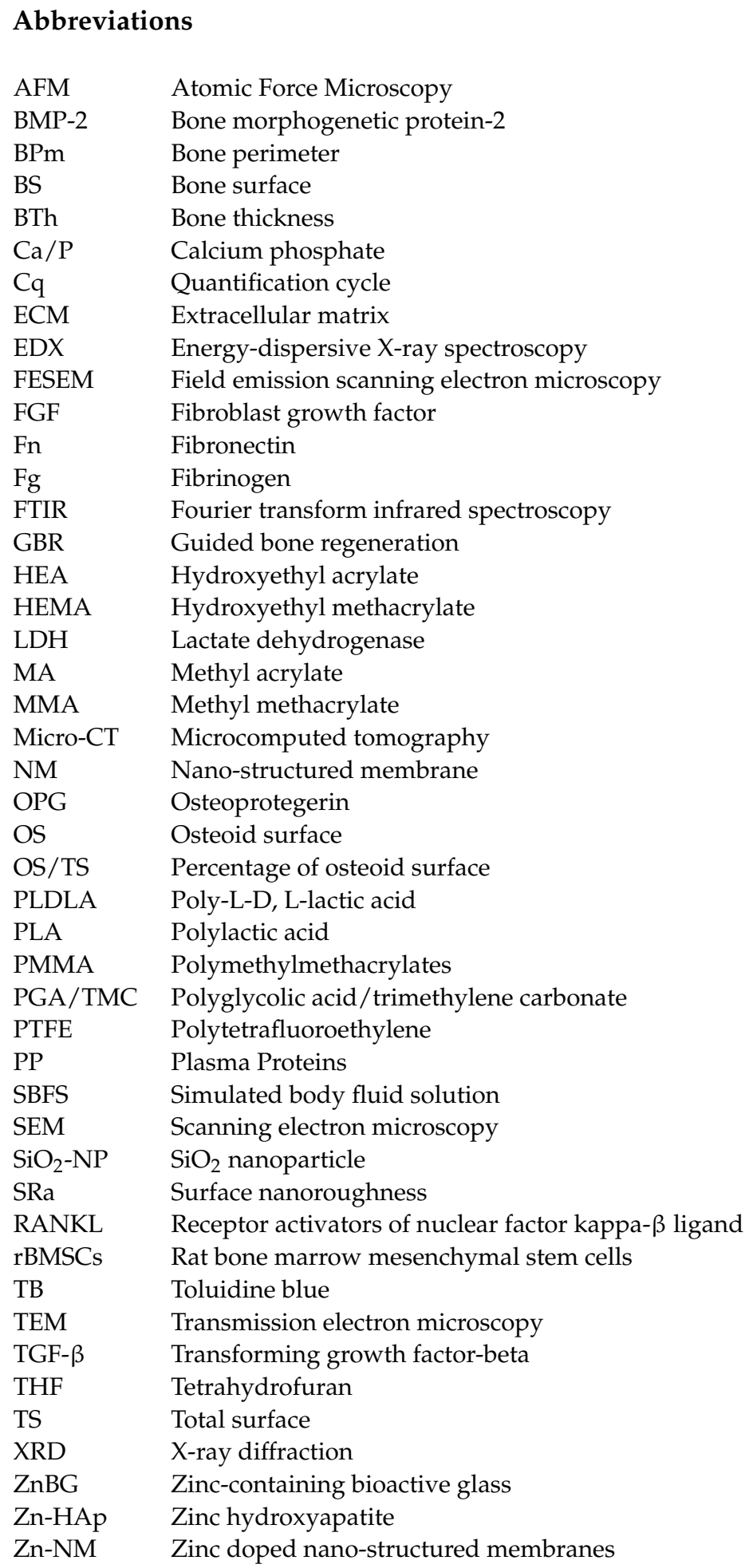

\section{References}

1. Resende, M.; Martinez, E.F. Topographic Characterization and in Vitro Biofilm Adhesion to Titanium and Polypropylene Membranes Used for Alveolar Preservation. J. Indian Soc. Periodontol. 2020, 24, 316-321. [CrossRef] [PubMed]

2. Schropp, L.; Wenzel, A.; Kostopoulos, L.; Karring, T. Bone Healing and Soft Tissue Contour Changes Following Single-Tooth Extraction: A Clinical and Radiographic 12-Month Prospective Study. Int. J. Periodontics Restor. Dent. 2003, 23, 313-323.

3. Sheikh, Z.; Sima, C.; Glogauer, M. Bone Replacement Materials and Techniques Used for Achieving Vertical Alveolar Bone Augmentation. Materials 2015, 8, 2953-2993. [CrossRef] 
4. Münchow, E.A.; Albuquerque, M.T.P.; Zero, B.; Kamocki, K.; Piva, E.; Gregory, R.L.; Bottino, M.C. Development and Characterization of Novel ZnO-Loaded Electrospun Membranes for Periodontal Regeneration. Dent. Mater. 2015, 31, 1038-1051. [CrossRef] [PubMed]

5. Zafar, M.S.; Khurshid, Z.; Almas, K. Oral Tissue Engineering Progress and Challenges. Tissue Eng. Regen. Med. 2015, 12, 387-397. [CrossRef]

6. Toledano, M.; Toledano-Osorio, M.; Osorio, R.; Carrasco-Carmona, Á.; Gutiérrez-Pérez, J.-L.; Gutiérrez-Corrales, A.; SerreraFigallo, M.-A.; Lynch, C.D.; Torres-Lagares, D. Doxycycline and Zinc Loaded Silica-Nanofibrous Polymers as Biomaterials for Bone Regeneration. Polymers 2020, 12, 1201. [CrossRef]

7. Shaikh, M.S.; Zafar, M.S.; Pisani, F.; Lone, M.A.; Malik, Y.R. Critical Features of Periodontal Flaps with Regard to Blood Clot Stability: A Review. J. Oral Biosci. 2021. [CrossRef] [PubMed]

8. Toledano-Osorio, M.; Manzano-Moreno, F.J.; Toledano, M.; Medina-Castillo, A.L.; Costela-Ruiz, V.J.; Ruiz, C.; Osorio, R. Doxycycline-Doped Polymeric Membranes Induced Growth, Differentiation and Expression of Antigenic Phenotype Markers of Osteoblasts. Polymers 2021, 13, 1063. [CrossRef] [PubMed]

9. Raj Preeth, D.; Saravanan, S.; Shairam, M.; Selvakumar, N.; Selestin Raja, I.; Dhanasekaran, A.; Vimalraj, S.; Rajalakshmi, S. Bioactive Zinc(II) Complex Incorporated PCL/Gelatin Electrospun Nanofiber Enhanced Bone Tissue Regeneration. Eur. J. Pharm. Sci. 2021, 160, 105768. [CrossRef]

10. Shaikh, M.S.; Husain, S.; Lone, M.A.; Lone, M.A.; Akhlaq, H.; Zafar, M.S. Clinical Effectiveness of Anorganic Bovine-Derived Hydroxyapatite Matrix/Cell-Binding Peptide Grafts for Regeneration of Periodontal Defects: A Systematic Review and MetaAnalysis. Regen. Med. 2020, 15, 2379-2395. [CrossRef]

11. Zhang, Y.; Zhang, X.; Shi, B.; Miron, R. Membranes for Guided Tissue and Bone Regeneration. Ann. Oral Maxillofac. Surg. 2013, 1, 1-10. [CrossRef]

12. Zhang, F.; Zhang, W.B.; Shi, Z.; Wang, D.; Jin, J.; Jiang, L. Nanowire-Haired Inorganic Membranes with Superhydrophilicity and Underwater Ultralow Adhesive Superoleophobicity for High-Efficiency Oil/Water Separation. Adv. Mater. 2013, 25, 4192-4198. [CrossRef] [PubMed]

13. Toledano-Osorio, M.; Toledano, M.; Manzano-Moreno, F.J.; Vallecillo, C.; Vallecillo-Rivas, M.; Rodriguez-Archilla, A.; Osorio, R. Alveolar Bone Ridge Augmentation Using Polymeric Membranes: A Systematic Review and Meta-Analysis. Polymers 2021, 13, 1172. [CrossRef]

14. Zhang, Y.; Yan, Y.; Xu, X.; Lu, Y.; Chen, L.; Li, D.; Dai, Y.; Kang, Y.; Yu, K. Investigation on the Microstructure, Mechanical Properties, in Vitro Degradation Behavior and Biocompatibility of Newly Developed Zn-0.8\%Li-(Mg, Ag) Alloys for Guided Bone Regeneration. Mater. Sci. Eng. C. Mater. Biol. Appl. 2019, 99, 1021-1034. [CrossRef]

15. Hürzeler, M.B.; Quiñones, C.R.; Schüpbach, P. Guided Bone Regeneration around Dental Implants in the Atrophic Alveolar Ridge Using a Bioresorbable Barrier. An Experimental Study in the Monkey. Clin. Oral Implants Res. 1997, 8, 323-331. [CrossRef]

16. Sauro, S.; Mannocci, F.; Toledano, M.; Osorio, R.; Thompson, I.; Watson, T.F. Influence of the Hydrostatic Pulpal Pressure on Droplets Formation in Current Etch-and-Rinse and Self-Etch Adhesives: A Video Rate/TSM Microscopy and Fluid Filtration Study. Dent. Mater. 2009, 25, 1392-1402. [CrossRef]

17. Punet, X.; Mauchauffé, R.; Rodríguez-Cabello, J.C.; Alonso, M.; Engel, E.; Mateos-Timoneda, M.A. Biomolecular Functionalization for Enhanced Cell-Material Interactions of Poly(Methyl Methacrylate) Surfaces. Regen. Biomater. 2015, 2, 167-175. [CrossRef]

18. Osorio, R.; Alfonso-Rodríguez, C.A.; Osorio, E.; Medina-Castillo, A.L.; Alaminos, M.; Toledano-Osorio, M.; Toledano, M. Novel Potential Scaffold for Periodontal Tissue Engineering. Clin. Oral Investig. 2017, 21, 2695-2707. [CrossRef]

19. Kim, S.; Hwang, Y.; Kashif, M.; Jeong, D.; Kim, G. Evaluation of Bone Regeneration on Polyhydroxyethyl-Polymethyl Methacrylate Membrane in a Rabbit Calvarial Defect Model. In Vivo 2016, 30, 587-591.

20. Toledano, M.; Carrasco-Carmona, Á.; Medina-Castillo, A.L.; Toledano-Osorio, M.; Osorio, R. Protein Adsorption and Bioactivity of Functionalized Electrospun Membranes for Bone Regeneration. J. Dent. 2020, 102, 103473. [CrossRef]

21. Esfahani, H.; Prabhakaran, M.P.; Salahi, E.; Tayebifard, A.; Keyanpour-Rad, M.; Rahimipour, M.R.; Ramakrishna, S. Protein Adsorption on Electrospun Zinc Doped Hydroxyapatite Containing Nylon 6 Membrane: Kinetics and Isotherm. J. Colloid Interface Sci 2015, 443, 143-152. [CrossRef] [PubMed]

22. Lu, A.; Wu, Z.; Luo, X.; Li, S. Protein Adsorption and Macrophage Uptake of Zwitterionic Sulfobetaine Containing Micelles. Coll. Surf. B Biointerfaces 2018, 167, 252-259. [CrossRef]

23. Griffin, M.F.; Ibrahim, A.; Seifalian, A.M.; Butler, P.E.M.; Kalaskar, D.M.; Ferretti, P. Chemical Group-Dependent Plasma Polymerisation Preferentially Directs Adipose Stem Cell Differentiation towards Osteogenic or Chondrogenic Lineages. Acta Biomater. 2017, 50, 450-461. [CrossRef]

24. Hirata, I.; Akamatsu, M.; Fujii, E.; Poolthong, S.; Okazaki, M. Chemical Analyses of Hydroxyapatite Formation on SAM Surfaces Modified with $\mathrm{COOH}, \mathrm{NH}(2), \mathrm{CH}(3)$, and $\mathrm{OH}$ Functions. Dent. Mater. J. 2010, 29, 438-445. [CrossRef]

25. Toledano-Osorio, M.; Manzano-Moreno, F.J.; Ruiz, C.; Toledano, M.; Osorio, R. Testing Active Membranes for Bone Regeneration: A Review. J. Dent. 2021, 105, 103580. [CrossRef]

26. Chou, J.; Komuro, M.; Hao, J.; Kuroda, S.; Hattori, Y.; Ben-Nissan, B.; Milthorpe, B.; Otsuka, M. Bioresorbable Zinc Hydroxyapatite Guided Bone Regeneration Membrane for Bone Regeneration. Clin. Oral Implants Res. 2016, 27, 354-360. [CrossRef]

27. Fraga, C.G.; Oteiza, P.I.; Keen, C.L. Trace Elements and Human Health. Mol. Aspects Med. 2005, 26, 233-234. [CrossRef] 
28. Bueno, J.; Sánchez, M.C.; Toledano-Osorio, M.; Figuero, E.; Toledano, M.; Medina-Castillo, A.L.; Osorio, R.; Herrera, D.; Sanz, M. Antimicrobial Effect of Nanostructured Membranes for Guided Tissue Regeneration: An in Vitro Study. Dent. Mater. 2020, 36, 1566-1577. [CrossRef]

29. Osorio, R.; Carrasco-Carmona, Á.; Toledano, M.; Osorio, E.; Medina-Castillo, A.L.; Iskandar, L.; Marques, A.; Deb, S.; ToledanoOsorio, M. Ex Vivo Investigations on Bioinspired Electrospun Membranes as Potential Biomaterials for Bone Regeneration. J. Dent. 2020, 98, 103359. [CrossRef]

30. Toledano, M.; Gutierrez-Pérez, J.L.; Gutierrez-Corrales, A.; Serrera-Figallo, M.A.; Toledano-Osorio, M.; Rosales-Leal, J.I.; Aguilar, M.; Osorio, R.; Torres-Lagares, D. Novel Non-Resorbable Polymeric-Nanostructured Scaffolds for Guided Bone Regeneration. Clin. Oral Investig. 2020, 24, 2037-2049. [CrossRef] [PubMed]

31. Ferrari, R. Writing Narrative Style Literature Reviews. Med. Writ. 2015, 24, 230-235. [CrossRef]

32. Chou, A.H.K.; LeGeros, R.Z.; Chen, Z.; Li, Y. Antibacterial Effect of Zinc Phosphate Mineralized Guided Bone Regeneration Membranes. Implant. Dent. 2007, 16, 89-100. [CrossRef] [PubMed]

33. LeGeros, R.Z.; Lin, S.; Rohanizadeh, R.; Mijares, D.; LeGeros, J.P. Biphasic Calcium Phosphate Bioceramics: Preparation, Properties and Applications. J. Mater. Sci. Mater. Med. 2003, 14, 201-209. [CrossRef] [PubMed]

34. Oh, S.-A.; Won, J.-E.; Kim, H.-W. Composite Membranes of Poly(Lactic Acid) with Zinc-Added Bioactive Glass as a Guiding Matrix for Osteogenic Differentiation of Bone Marrow Mesenchymal Stem Cells. J. Biomater. Appl. 2012, 27, 413-422. [CrossRef]

35. Will, J.; Detsch, R.; Boccaccini, A.R. Chapter 7.1-Structural and Biological Characterization of Scaffolds. In Characterization of Biomaterials; Bandyopadhyay, A., Bose, S., Eds.; Academic Press: Oxford, UK, 2013; pp. 299-310. ISBN 978-0-12-415800-9.

36. Vallee, B.L.; Falchuk, K.H. The Biochemical Basis of Zinc Physiology. Physiol. Rev. 1993, 73, 79-118. [CrossRef]

37. Park, Y.J.; Ku, Y.; Chung, C.P.; Lee, S.J. Controlled Release of Platelet-Derived Growth Factor from Porous Poly(L-Lactide) Membranes for Guided Tissue Regeneration. J. Control. Release 1998, 51, 201-211. [CrossRef]

38. Owen, G.R.; Jackson, J.; Chehroudi, B.; Burt, H.; Brunette, D.M. A PLGA Membrane Controlling Cell Behaviour for Promoting Tissue Regeneration. Biomaterials 2005, 26, 7447-7456. [CrossRef]

39. Ku, Y.; Shim, I.K.; Lee, J.Y.; Park, Y.J.; Rhee, S.-H.; Nam, S.H.; Park, J.B.; Chung, C.P.; Lee, S.J. Chitosan/Poly(L-Lactic Acid) Multilayered Membrane for Guided Tissue Regeneration. J. Biomed. Mater. Res. A 2009, 90, 766-772. [CrossRef]

40. Iijima, K.; Iizuka, A.; Suzuki, R.; Ueno-Yokohata, H.; Kiyokawa, N.; Hashizume, M. Effect of Protein Adsorption Layers and Solution Treatments on Hydroxyapatite Deposition on Polystyrene Plate Surfaces in Simulated Body Fluids. J. Mater. Sci. Mater. Med. 2017, 28, 193. [CrossRef]

41. Liu, D.P.; Majewski, P.; O’Neill, B.K.; Ngothai, Y.; Colby, C.B. The Optimal SAM Surface Functional Group for Producing a Biomimetic HA Coating on Ti. J. Biomed. Mater. Res. A 2006, 77, 763-772. [CrossRef]

42. Osorio, R.; Aguilera, F.S.; Otero, P.R.; Romero, M.; Osorio, E.; García-Godoy, F.; Toledano, M. Primary Dentin Etching Time, Bond Strength and Ultra-Structure Characterization of Dentin Surfaces. J. Dent. 2010, 38, 222-231. [CrossRef]

43. ISO 23317:2012. Implants for Surgery — In Vitro Evaluation for Apatite-Forming Ability of Implant Materials, 2nd ed.; ISO: Geneva, Switzerland, 2012.

44. Yiu, C.K.Y.; Tay, F.R.; King, N.M.; Pashley, D.H.; Sidhu, S.K.; Neo, J.C.L.; Toledano, M.; Wong, S.L. Interaction of Glass-Ionomer Cements with Moist Dentin. J. Dent. Res. 2004, 83, 283-289. [CrossRef]

45. Pietak, A.M.; Reid, J.W.; Stott, M.J.; Sayer, M. Silicon Substitution in the Calcium Phosphate Bioceramics. Biomaterials 2007, 28, 4023-4032. [CrossRef] [PubMed]

46. Chai, Y.C.; Carlier, A.; Bolander, J.; Roberts, S.J.; Geris, L.; Schrooten, J.; Van Oosterwyck, H.; Luyten, F.P. Current Views on Calcium Phosphate Osteogenicity and the Translation into Effective Bone Regeneration Strategies. Acta Biomater. 2012, 8 , 3876-3887. [CrossRef]

47. Tada, H.; Nemoto, E.; Kanaya, S.; Hamaji, N.; Sato, H.; Shimauchi, H. Elevated Extracellular Calcium Increases Expression of Bone Morphogenetic Protein-2 Gene via a Calcium Channel and ERK Pathway in Human Dental Pulp Cells. Biochem. Biophys. Res. Commun. 2010, 394, 1093-1097. [CrossRef]

48. Shimauchi, H.; Nemoto, E.; Ishihata, H.; Shimomura, M. Possible Functional Scaffolds for Periodontal Regeneration. Jpn. Dent. Sci. Rev. 2013, 49, 118-130. [CrossRef]

49. Kanaya, S.; Nemoto, E.; Sakisaka, Y.; Shimauchi, H. Calcium-Mediated Increased Expression of Fibroblast Growth Factor-2 Acts through NF-KB and PGE2/EP4 Receptor Signaling Pathways in Cementoblasts. Bone 2013, 56, 398-405. [CrossRef] [PubMed]

50. Rubin, M.R.; Zhou, H.; Cusano, N.E.; Majeed, R.; Omeragic, B.; Gomez, M.; Nickolas, T.L.; Dempster, D.W.; Bilezikian, J.P. The Effects of Long-Term Administration of RhPTH(1-84) in Hypoparathyroidism by Bone Histomorphometry. J. Bone Miner. Res. 2018, 33, 1931-1939. [CrossRef] [PubMed]

51. Parfitt, A.M.; Drezner, M.K.; Glorieux, F.H.; Kanis, J.A.; Malluche, H.; Meunier, P.J.; Ott, S.M.; Recker, R.R. Bone Histomorphometry: Standardization of Nomenclature, Symbols, and Units. Report of the ASBMR Histomorphometry Nomenclature Committee. J. Bone Miner. Res. 1987, 2, 595-610. [CrossRef]

52. La Monaca, G.; Iezzi, G.; Cristalli, M.P.; Pranno, N.; Sfasciotti, G.L.; Vozza, I. Comparative Histological and Histomorphometric Results of Six Biomaterials Used in Two-Stage Maxillary Sinus Augmentation Model after 6-Month Healing. Biomed. Res. Int. 2018, 2018, 9430989. [CrossRef] [PubMed] 
53. Fujioka-Kobayashi, M.; Kobayashi, E.; Schaller, B.; Mottini, M.; Miron, R.J.; Saulacic, N. Effect of Recombinant Human Bone Morphogenic Protein 9 (RhBMP9) Loaded onto Bone Grafts versus Barrier Membranes on New Bone Formation in a Rabbit Calvarial Defect Model. J. Biomed. Mater. Res. A 2017, 105, 2655-2661. [CrossRef] [PubMed]

54. Maggiano, I.S.; Maggiano, C.M.; Clement, J.G.; Thomas, C.D.L.; Carter, Y.; Cooper, D.M.L. Three-Dimensional Reconstruction of Haversian Systems in Human Cortical Bone Using Synchrotron Radiation-Based Micro-CT: Morphology and Quantification of Branching and Transverse Connections across Age. J. Anat. 2016, 228, 719-732. [CrossRef]

55. Udagawa, A.; Sato, S.; Hasuike, A.; Kishida, M.; Arai, Y.; Ito, K. Micro-CT Observation of Angiogenesis in Bone Regeneration. Clin. Oral Implants Res. 2013, 24, 787-792. [CrossRef]

56. Liu, W.; Li, J.; Cheng, M.; Wang, Q.; Yeung, K.W.K.; Chu, P.K.; Zhang, X. Zinc-Modified Sulfonated Polyetheretherketone Surface with Immunomodulatory Function for Guiding Cell Fate and Bone Regeneration. Adv. Sci. 2018, 5, 1800749. [CrossRef]

57. Dey, A.; Bomans, P.H.H.; Müller, F.A.; Will, J.; Frederik, P.M.; de With, G.; Sommerdijk, N.A.J.M. The Role of Prenucleation Clusters in Surface-Induced Calcium Phosphate Crystallization. Nat. Mater. 2010, 9, 1010-1014. [CrossRef] [PubMed]

58. Guarnieri, R.; Belleggia, F.; DeVillier, P.; Testarelli, L. Histologic and Histomorphometric Analysis of Bone Regeneration with Bovine Grafting Material after 24 Months of Healing. A Case Report. J. Funct. Biomater. 2018, 9, 48. [CrossRef] [PubMed]

59. Toledano, M.; Yamauti, M.; Ruiz-Requena, M.E.; Osorio, R. A ZnO-Doped Adhesive Reduced Collagen Degradation Favouring Dentine Remineralization. J. Dent. 2012, 40, 756-765. [CrossRef]

60. Woo, K.M.; Chen, V.J.; Ma, P.X. Nano-Fibrous Scaffolding Architecture Selectively Enhances Protein Adsorption Contributing to Cell Attachment. J. Biomed. Mater. Res. A 2003, 67, 531-537. [CrossRef]

61. Bružauskaitè, I.; Bironaite,, D.; Bagdonas, E.; Bernotienè, E. Scaffolds and Cells for Tissue Regeneration: Different Scaffold Pore Sizes-Different Cell Effects. Cytotechnology 2016, 68, 355-369. [CrossRef]

62. Polly, B.J.; Yuya, P.A.; Akhter, M.P.; Recker, R.R.; Turner, J.A. Intrinsic Material Properties of Trabecular Bone by Nanoindentation Testing of Biopsies Taken from Healthy Women before and after Menopause. Calcif. Tissue Int. 2012, 90, 286-293. [CrossRef]

63. Xu, B.; Chow, M.-J.; Zhang, Y. Experimental and Modeling Study of Collagen Scaffolds with the Effects of Crosslinking and Fiber Alignment. Int. J. Biomater. 2011, 2011, 172389. [CrossRef]

64. Baker, B.M.; Trappmann, B.; Wang, W.Y.; Sakar, M.S.; Kim, I.L.; Shenoy, V.B.; Burdick, J.A.; Chen, C.S. Cell-Mediated Fibre Recruitment Drives Extracellular Matrix Mechanosensing in Engineered Fibrillar Microenvironments. Nat. Mater. 2015, 14, 1262-1268. [CrossRef] [PubMed]

65. Agrawal, R.; Nieto, A.; Chen, H.; Mora, M.; Agarwal, A. Nanoscale Damping Characteristics of Boron Nitride Nanotubes and Carbon Nanotubes Reinforced Polymer Composites. ACS Appl. Mater. Interfaces 2013, 5, 12052-12057. [CrossRef] [PubMed]

66. Toledano, M.; Aguilera, F.S.; Osorio, E.; Cabello, I.; Toledano-Osorio, M.; Osorio, R. Self-Etching Zinc-Doped Adhesives Improve the Potential of Caries-Affected Dentin to Be Functionally Remineralized. Biointerphases 2015, 10, 031002. [CrossRef] [PubMed]

67. Vijver, M.G.; van Gestel, C.A.M.; van Straalen, N.M.; Lanno, R.P.; Peijnenburg, W.J.G.M. Biological Significance of Metals Partitioned to Subcellular Fractions within Earthworms (Aporrectodea Caliginosa). Environ. Toxicol. Chem. 2006, 25, 807-814. [CrossRef] [PubMed]

68. Guo, H.; Xia, D.; Zheng, Y.; Zhu, Y.; Liu, Y.; Zhou, Y. A Pure Zinc Membrane with Degradability and Osteogenesis Promotion for Guided Bone Regeneration: In Vitro and in Vivo Studies. Acta Biomater. 2020, 106, 396-409. [CrossRef]

69. Augustine, R.; Dominic, E.A.; Reju, I.; Kaimal, B.; Kalarikkal, N.; Thomas, S. Electrospun Polycaprolactone Membranes Incorporated with ZnO Nanoparticles as Skin Substitutes with Enhanced Fibroblast Proliferation and Wound Healing. RSC Adv. 2014, 4, 24777-24785. [CrossRef]

70. Bottino, M.C.; Thomas, V.; Schmidt, G.; Vohra, Y.K.; Chu, T.-M.G.; Kowolik, M.J.; Janowski, G.M. Recent Advances in the Development of GTR/GBR Membranes for Periodontal Regeneration-A Materials Perspective. Dent. Mater. 2012, 28, 703-721. [CrossRef] 